\title{
Ambalaj Atığı Toplama-Ayırma Tesisi Etkinliklerinin Hibrid bir Model Önerisi ile İncelenmesi ${ }^{1}$
}

\section{Investigation of Packaging Waste Collection-Separation Facility Efficiencies with a Hybrid Model Proposal}

\section{Dr. Öğr. Üyesi Talip ARSU² - Doç. Dr. Nurullah UMARUSMAN³}

Başvuru Tarihi: 27.07.2019

Kabul Tarihi: 22.06.2020

Makale Türü: Araştırma Makalesi

Öz

Ambalaj atı̆̆ının çevre üzerindeki olumsuz etkisi ve bakir kaynakların kullanımından kaynaklı ekonomik kayıplar, geri dönüşüm sürecini zorunlu hale getirmiştir. Geri dönüşüm sürecindeki en önemli aşama olan ambalaj atığının toplanması ve kategorilerine göre ayrıştırılması işlemlerinin başarısı, bu işlemlerin etkin bir şekilde yönetilmesine bağlıdır. Türkiye'de ambalaj atıklarının toplanması ve kategorilerine göre ayrıştırılması işlemini Toplama-Ayırma Tesisleri (TAT) üstlenmektedir. Bu çalı̧̧mada, Çok Amaçlı Karar Verme (ÇAKV) yöntemlerinden Çok Amaçlı Doğrusal Programlama (ÇADP) ile modellenen Çok Kriterli Veri Zarflama Analizi (ÇKVZA) Global Kriter Yöntem kullanılarak çözülmüştür. Önerilen yeni yöntem Global-Çok Kriterli Veri Zarflama Analizi (G-ÇKVZA) olarak isimlendirilmiştir. Çalışma sonucunda İç Anadolu Bölgesinde faaliyetlerini sürdüren 67 tesisten 6’sı etkin tesisler olarak bulunmuştur.

Anahtar Kelimeler: Toplama-Ayırma Tesisleri (TAT), Çok Kriterli Veri Zarflama Analizi (ÇKVZA), Global Kriter Yöntem, Global-Çok Kriterli Veri Zarflama Analizi (G-ÇKVZA)

\begin{abstract}
The negative impact of packaging waste on the environment and the economic losses caused by the use of virgin resources have made the recycling process mandatory. The success of the process of collecting and sorting the packaging waste, which is the most important step in the recycling process, depends on the effective management of these processes. Collection-Separation Facilities (CSF) undertaken the process of collecting and separating according to category of packaging wastes. In this study, Multi Criteria Data Envelopment Analysis (MCDEA), which was modeled with Multi-Objective Linear Programming(MOLP) from Multi-Objective Decision Making (MODM) methods, was solved by using Global Criterion Method. The proposed new method is named as Global-Multi Criteria Data Envelopment Analysis (G-MCDEA). As a result of the study, 6 of the 67 facilities operating in the Central Anatolia Region were found to be efficient facilities.
\end{abstract}

Keywords: Collection-Separation Facility (CSF), Multi Criteria Data Envelopment Analysis (MCDEA), Global Criterion Method, Global- Multi Criteria Data Envelopment Analysis (G$M C D E A)$

\footnotetext{
${ }^{1}$ Bu çalışma 31.12.2018 tarihinde Aksaray Üniversitesi, Sosyal Bilimler Enstitüsü, İşletme Doktora Programında doktora tezi olarak savunulmuștur.

2 Aksaray Üniversitesi Sosyal Bilimler Meslek Yüksek Okulu, taliparsu@aksaray.edu.tr, ORCID: 0000-0002-2580-166X

${ }^{3}$ Aksaray Üniversitesi İktisadi ve İdari Bilimler Fakültesi, nurullah.umarusman@aksaray.edu.tr, ORCID: 0000-0001-6535-5329
} 


\section{Giriş}

Muhafaza, kolay taşınabilirlik, tutundurma gibi birçok fonksiyonu yerine getiren ambalajlar, hem işletmeleri fazladan bir maliyetin altına sokmakta, hem de bu ambalajların atıkları çevreye geri dönüşü olmayan zararlar vermektedir. Bu zararların farkında olan birçok ülke farklı toplama sistemleri geliştirilmiş olmasına rağmen Türkiye'de toplama işlemini belediyeler veya Çevre ve Şehircilik Bakanlığı (ÇŞB) tarafından yetkilendirilen Toplama-Ayırma Tesisleri (TAT) üstlenmektedir. $\mathrm{Bu}$ tesisler, kaynağında ayrı toplama sistemi ile atık toplama işlemi yapmaktadır. Kaynağında ayrı toplanan bu atıklar tesislere getirildikten sonra ise türlerine göre kağıt, plastik, cam, metal vb. ayrılarak tekrar işlenmek üzere Geri Dönüşüm Tesislerine (GDT) yollanmaktadır. Çalışma prensibi bu temeller üzerine kurulu olan tesislerin başarısı, toplama ve ayırma süreçlerinin etkin bir şekilde yönetilmesine bağlıdır. Bu noktadan hareketle, çalışmanın birinci amacı TAT'ların faaliyette bulunduğu bölgenin, bu bölgedeki demografik yapının, tesisin gelir-gider dengesinin ve tesis süreçlerinin nicel verileri kullanılarak tesislerin etkinliğini incelemek olarak belirlenmiştir.

Tersine lojistik benzeri kavramlar çok eskilerden beri kullanılıyor olsa da ilk olarak 70'li yıllarda “Tersine dağıtım” ve "tersine akış" kavramları bir akademik makalede (Zikmund ve Stanton, 1971) kullanılmıştır. Yetmişli yılların ortalarında ise Guiltinan ve Nwokoye (1975), Ginter ve Starling (1978) tersine lojistikten çalışmalarında "tersine kanallar” veya "tersine akış" olarak bahsetmiştir. Tersine lojistik terimi ilk olarak 1981 yılında Lambert ve Stock tarafından kullanılmıştır. Lambert ve Stock tersine lojistiği "tek yönlü bir yolda yanlış yöne gitmek yani ürünlerin büyük çoğunluğunun ters yönde akışı” olarak tanımlamışlardır (Rogers ve TibbenLembke, 2001, s.129). Tersine lojistik, ürün geri kazanım yöntemlerine göre farklı biçimlerde sınıflandırılabilir. Geri kazanım yöntemleri içerisinde yeniden kullanım/yeniden satış, tamir, yenileştirme, yeniden üretim, parça alma ve geri dönüşüm sayılabilir (Kim vd., 2006).

Geri dönüşümün amacı, çeşitli ayırma süreçleri tarafından, kullanılan ürünler ve parçalardan, orijinal yada diğer ürünlerin üretiminde tekrar kullanmak için yeniden kullanılabilir malzemeler elde etmektir (Wadhwa vd., 2009, s.462). Geri dönüşümde malzeme geri kazanımı durumunda, ürünler genellikle öğütülür ve özellikleri ile kalite düzeylerine göre gruplandırılıp yeni ürün üretiminde kullanılabilir hale getirilir (Wiel vd., 2012, s.101).

Türkiye'de de geri dönüşümün ilk adımı olan toplama ve ayırma faaliyetini gerçekleştiren TAT'lar tarafından toplanan ambalaj atıkları, kâğıt/karton/mukavva, plastik/pet, cam, metal, alüminyum, kompozit, tekstil ve tahta olarak sıralanabilir. Bu materyallerden en yaygın olarak geri dönüşüme tabii tutulanlar ise kâğıt/karton/mukavva, plastik/pet, cam ve metallerdir. Bu yüzden bu çalışmada ambalaj atıkları kağıt, plastik, cam ve metal ambalaj atıkları olarak sınıflandırılmıştır.

Literatür incelendiğinde TAT'ların etkinliğini konu alan bir çalışmaya rastlanamamıştır. Ancak evsel atık geri dönüşümü, belediye katı atık yönetimi hizmetleri gibi konularda etkinlik incelemelerinin yapıldığı görülmüştür. Bosch vd. (2000), çöp toplama hizmetlerinin teknik verimliliğini, Worthington ve Dollery (2001), evsel atık yönetimi fonksiyonunun teknik ve ölçek etkinliğini, Lozano vd. (2004), geri dönüştürülmüş cam miktarı açısından belediyelerin etkinliğini, Chiou vd. (2005), katı atık yönetimi, geri dönüşüm ve işleme hizmetlerinin performansını, García-Sánchez (2008), sokak temizleme ve atık yönetimi hizmetlerinin 
verimliliğini, Marques ve Simões (2009), katı atık yönetiminin performansını, Chen (2010), evsel katı atık üretim, toplama ve ayırma performansını, Khadivi ve Ghomi (2012), katı atık tesislerine uygun alanın seçilmesi, Rogge ve De Jaeger (2012), katı atık toplama ve işleme etkinliğini, Chang vd. (2013), katı atık geri dönüşüm sistemlerinin etkinliğini, Ichinose vd. (2013), katı atık lojistiğinin etkinliğini, De Jaeger ve Rogge (2014), evsel ambalaj atıklarının toplanmasının maliyet etkinliğini ve Exposito ve Velasco (2018), geri dönüşüm pazarının geliştirilmesinde bölgelerin etkinliğini, VZA kullanarak incelemiştir.

Etkinlik incelemesi yapılırken klasik Veri Zarflama Analizi (VZA) tabanlı parametrik olmayan bir yöntem olan Çok Kriterli Veri Zarflama Analizinden (ÇKVZA) yararlanılmıştır. Fakat ÇKVZA modeli yapısı gereği karar vericilere üç farklı etkinlik değeri arasından karar verme sorumluluğu yüklemektedir. Bu çalışmada subjektif yargılarla karar vermenin getireceği olumsuzlukların önüne geçmek amacıyla Global- Çok Kriterli Veri Zarflama Analizi (GÇKVZA) modeli önerilmiştir. Çalışmanın ikinci amacı ise yapılan uygulama ile önerilen hibrid modelin çözüm prosedürü ve çözüm algoritmalarını açılamak olarak belirlenmiştir.

G-ÇKVZA'nın temeli olan ÇKVZA modeli Li ve Reeves (1999) tarafından geliştirildikten sonra yıllar içerisinde birçok çalışmada uygulanmıştır. Zhao vd. (2006) bir baraj tasarımının çevresel etki değerlendirmesi için, San Cristóbal (2011) yenilenebilir enerji teknolojisini incelemek için, Alizadeh vd. (2011) bulanık ortamdaki konumlandırma ve atama problemlerinin çözümü için, Yadav vd. (2012) kömür yakıtlı termik santrallerin bölgesel etkinliğini ölçmek için, Rubem ve Brandao (2015) ulusal takımların performans etkinliklerini incelemek için ve Verma vd. (2016) yeni sanayi bölgesinde dağıtım ağı yerleşim planlaması yapmak için ÇKVZA kullanmıştır. Ayrıca Bal vd. (2010), Hedef Programlamayı kullanarak ağırlık dağılımının homojenliğini ölçmek için ÇKVZA'ya dayanan iki yeni model önermiş ve Ghasemi vd. (2014) klasik VZA'nın düşük ayrım gücü ve ağırlık dağılımının zayıflı̆̆ına atıf yaparak ÇKVZA tabanlı yeni bir model geliştirmiştir. Fakat Literatürde ÇKVZA'nın üç farklı amacını tek bir amaca dönüştürürken Global Kriter Yöntem kullanan herhangi bir çalışmaya rastlanamamıştır.

Önerilen Global Kriter Yöntem tabanlı G- ÇKVZA ile üç farklı amaç fonksiyonu tek bir amaç fonksiyonuna dönüştürülüp her bir Karar Verme Birimi (KVB) için çözüm gerçekleştirilmiştir. Ayrıca her bir KVB'nin üç amacı için ideal çözümden uzaklıklarının normalleştirilmiş derecesi hesaplanıp, global etkinliğin hangi amaca daha yakın gerçekleştiği belirlenmiştir.

Türkiye'deki TAT’ların etkinliğini incelemek amacıyla kurgulanan çalışmada öncelikle önerilen G-ÇKVZA yöntemi tanıtılarak uygulama adımları gösterilmiştir. Daha sonra önerilen modelin uygulandığı örneklem ve veriler tanıtılmıştır. Son olarak ulaşılan bilgiler ışı̆̆ında sektöre, kamu kuruluşlarına ve gelecekte yapılabilecek akademik çalışmalara önerilerde bulunulmuştur.

\section{Yöntem}

\section{Araştırmanın Amacı}

Araştırmanın iki amacı vardır. Birincisi, TAT’ların faaliyette bulunduğu bölgenin, bu bölgedeki demografik yapının, tesisin gelir-gider dengesinin ve tesis süreçlerinin nicel verileri kullanılarak tesislerin etkinliğini belirlemektir. Geri dönüşüm işleminin başarısında anahtar rol üstlenen 
toplama/ayırma sürecinin daha etkin yönetilmesi gerekliliği düşünülerek yapılan bu çalışma sonucunda, elde edilen bulgular kullanılarak belediyelere, tesislere ve ÇŞB’ye öneriler yapılmıştır.

Alanyazında VZA'nın farklı türleri (Hedef Programlama VZA, VZA-Analitik Hiyerarşi Prosesi vb.) ile etkinlik araştırmaları yapılmaktadır. Bu çalışmada Global Kriter Yöntem ve ÇKVZA hibrit bir model haline getirilerek G-ÇKVZA olarak isimlendirilmiştir. Araştırmanın ikinci amacı ise yapılan uygulama ile önerilen hibrit modelin çözüm prosedürü ve çözüm algoritmalarını açıklamaktır.

\section{Araştırma Verilerinin Analizinde Kullanılan Yöntemler}

Araştırma verilerinin analizinde Global Kriter Yöntem ve ÇKVZA tabanlı önerilen G- ÇKVZA modeli kullanılmıştır.

\section{Global Kriter Yöntem}

Tercih bilgilerine ihtiyaç duymayan sınıflandırmanın temel metodu olan Global Kriter Yöntemin amac1, kriterlerin mümkün olan ideal noktalardan sapmalarını minimize etmektir (Hwang ve Masud, 1979, s.21). Bu yöntem bütün amaç fonksiyonlarını tek bir amaç fonksiyonuna dönüştüren minimizasyon yöntemi olarak tanımlanır (Arora, 2012, s.673). Global kriter yöntemi, karar uzayındaki uygun bölgede yer alan bazı ideal referans noktaları arasındaki mesafeyi en aza indirir (French, 2018, s.207). Global kriter yöntemin en önemli avantajı, karar vericinin tercih bilgilerine ihtiyaç duyulmamasından dolayı, kararların sübjektif yargılar yerine çözümden elde edilen kantitatif veriler ile alınmasını sağlamaktır (Shih ve Chang, 1995, s.455). Global Kriter Yöntem matematiksel olarak aşağıdaki gibi gösterilir (Hwang ve Masud, 1979, s.21).

$\min \sum_{k=1}^{l}\left[\frac{Z_{k}{ }^{*}-Z_{k}(x)}{Z_{k}{ }^{*}}\right]^{p}$

$Z_{k}(x): k$-1ncı maksimizasyon yönlü amaç fonksiyonu,

$Z_{k}{ }^{*}: k$-incı amaç fonksiyonu için pozitif ideal çözüm.

Hwang ve Masud (1979) global formülasyonu maksimizasyon yönlü amaçlar için önermiştir. Diğer taraftan ÇADP problemleri sadece maksimizasyon yönlü amaçlardan oluşmamaktadır. Umarusman ve Türkmen (2013) tarafından önerilen bütün amaç fonksiyonları minimizasyon yönlü olan problemler için Global amaç fonksiyonunu aşağıdaki gibi düzenlemiştir.

$\operatorname{Min} \sum_{s=1}^{r}\left[\frac{W_{s}(x)-W_{s}^{*}}{W_{s}^{*}}\right]^{p}$

$W_{s}(x): k$-ıncı minimizasyon yönlü amaç fonksiyonu

$W_{s}^{*}: k$-1ncı amaç fonksiyonu için pozitif ideal çözüm

Bu çalışmada Umarusman ve Türkmen (2013) tarafından önerilen ağırlıksız global model kullanılmıştır. Model aşağıda verilmiştir;

$\operatorname{Min} G=\left(\sum_{k=1}^{l}\left[\frac{Z_{k}{ }^{*}-Z_{k}(x)}{Z_{k}{ }^{*}}\right]^{p}+\sum_{s=1}^{r}\left[\frac{W_{s}(x)-W_{s}{ }^{*}}{W_{s}{ }^{p}}\right]^{p}\right)$ 
Kisitlar

$A_{i}(x) \leq b_{i}$

$x \geq 0$

Global kriter yöntemi herhangi bir çözüm kümesi belirlenemediğinde nihai bir çözüm elde etmek için kullanılan basit bir yöntemdir. Yöntemde, global amaç değeri uygulanabilir amaç bölgesine daha yakın olan bir noktada gerçekleşmektedir (Miettinen, 1998, s.71).

\section{Çok Kriterli Veri Zarflama Analizi}

VZA Charnes vd. (1978) tarafindan Doğrusal Programlama problemi olarak sunulmuştur. Bu model alanyazında "Charnes Cooper Rhodes (CCR) model” olarak isimlendirilmiştir. Charnes vd. (1978) tarafından önerilen her bir KVB’nin etkinliğini değerlendirmek için tanımlanan doğrusal programlama modeli aşağıda verilmiştir.

Maks $h_{0}=\sum_{r=1}^{s} u_{r} y_{r j 0}$

Kisitlar

$\sum_{i=1}^{m} v_{i} x_{i j 0}=1$

$\sum_{r=1}^{s} u_{r} y_{r j}-\sum_{i=1}^{m} v_{i} x_{i j} \leq 0$

$j=1, \ldots . ., n$

$u_{r}, v_{i} \geq 0$

Bu modelde $j$ : KVB sayısı, $r$ : Çıktı sayısı, $i$ : Girdi sayısı, $y_{r j}: j$-inci KVB için $r$-inci çıktı değeri, $x_{i j}$ : $j$-inci KVB için $i$-inci girdi değeri, $u_{r}: r$-inci çıtıya verilen ağırlık, $v_{i}: i$-inci girdiye verilen ağırlık ve $h_{0}$ : Değerlendirilen KVB'nin nispi etkinliğini temsil etmektedir. (4)'de yalnızca $h_{0}=1$ ise KVB etkindir sonucuna varılır.

Klasik VZA için etkinlik bir ölçüm birimi olmakla birlikte Li ve Reeves (1999)'in ÇKVZA modeli etkisizlikler üzerine kurulmuştur. $[0,1]$ aralığg ile sınırlanan $d_{0}$, "etkisizlik" ölçüsü olarak kabul edilebilir ve $h_{0}=1-d_{o}$ olarak tanımlanır. Yani, $d_{0}$ değeri ne kadar küçük olursa, $\mathrm{KVB}_{0}$ daha az etkisizdir (ve dolayısıyla daha etkin) denilebilir. Li ve Reeves (1999)'in yöntemi $d_{0}$ 'ı en aza indirgemek, maksimum sapmayı en aza indirgemek veya sapmaların toplamını en aza indirgemek gibi bağımsız amaç fonksiyonlarından oluşur. Söz konusu model aşağıdaki gibidir;

Min $d_{0}$ (veya maks $\left.h_{0}=\sum_{r=1}^{s} u_{r} y_{r j 0}\right)$

$\operatorname{Min} M$

$\operatorname{Min} \sum_{j=1}^{n} d_{j}$

Kisitlar 


$$
\begin{aligned}
& \sum_{i=1}^{m} v_{i} x_{i j 0}=1 \\
& \sum_{r=1}^{s} u_{r} y_{r j}-\sum_{i=1}^{m} v_{i} x_{i j}+d_{j}=0 \\
& M-d_{j} \geq 0 \quad j=1, \ldots \ldots, n \\
& u_{r}, v_{i}, d_{j} \geq 0
\end{aligned}
$$

ÇKVZA modeli öncelikle klasik VZA modelinin ayrım gücünün geliştirilmesi için bir araç olarak önerilmiştir. Çözüm işlemlerinde, ÇKVZA üç amacın her birini çözmek için etkileşimli bir yaklaşım olarak önerilmiştir. İlk amaç ÇKVZA çözümlerinin kümesi içinde klasik VZA çözümünü barındırmaktadır. Diğer iki amaç olan Minmax ve Minsum amaçları sırasıyla daha kısıtlayıcı veya gevşek etkinlik çözümleri sunmaktadır. Bu model ile daha makul girdi ve çıktı ağırlıkları elde etmek için daha geniş bir çözümün mümkün olduğu kanıtlanmaktadır (Ghasemi vd., 2014, s.641).

\section{Global- Çok Kriterli Veri Zarflama Analizi (G-ÇKVZA)}

$\mathrm{Bu}$ çalışmada TAT’ların girdi veya çıktı olarak ifade edilen bilgileri, Li ve Reeves (1999) tarafından önerilen ÇKVZA modelinde kullanılmış ve bu modeldeki amaç fonksiyonlarının pozitif ideal çözümleri belirlenmiştir. Daha sonra Li ve Reeves (1999) tarafından önerilen ÇKVZA modelinin üç amacının tek bir amaca dönüştürülebilmesi için pozitif ideal çözümler kullanılarak problem yeniden düzenlenmiş ve Global Kriter Yöntem ile çözülmüştür. Önerilen bu yöntem “Global- Çok Kriterli Veri Zarflama Analizi (G-ÇKVZA)” olarak isimlendirilmiştir.

Li ve Reeves (1999)'in modelinde üç farklı amaç fonksiyonu mevcuttur. Önerilen G-ÇKVZA modelinde $\operatorname{Min} d_{0}$ amacı yerine $1-d_{0}$ sonucunu ifade eden Max $h_{0}$ amacı kullanılmıştır. Çünkü $\operatorname{Min}_{0}$ amacı kullanıldığında, $\operatorname{Min} d_{0}$ 'ın pozitif ideal çözümünün “0” değerine sahip olması mümkün olabilmektedir. Bu durum (2) denkleminde belirlenecek olan paydanın 0’a eşit olmasına sebep olabilir. Miettinen (1998) global amaç fonksiyonu oluşturulurken pozitif ideal çözümü 0 olan amaçların global amaçta yer alamayacağını savunmuştur. Bu sebeple önerilen algoritmada $\operatorname{Max} h_{0}$, Min $M$ ve Min $\sum d_{j}^{\prime}$ ye göre düzenleme yapılmıştır. Bu çalışmada, (3) kullanılarak önerilen G-ÇKVZA modelinin amaç fonksiyonu aşağıdaki gibi oluşturulmuştur.

$\operatorname{Min}\left[\frac{h_{0 j}^{*}-h_{0 j}}{h_{0 j}^{*}}+\frac{M_{j}-M_{j}^{*}}{M_{j}^{*}}+\frac{\sum_{j=1}^{n} d_{j}-d_{j}^{*}}{d_{j}^{*}}\right]^{p}$

Veya (6) sadeleştirilerek

$$
\operatorname{Min}\left[\left(\frac{M_{j}}{M_{j}^{*}}+\frac{\sum_{j=1}^{n} d_{j}}{d_{j}^{*}}-\frac{h_{0 j}}{h_{0 j}^{*}}\right)-1\right]^{p}
$$

Elde edilir. Bu amaç fonksiyonunda; $h_{0 j}=j$-inci KVB'nin etkinlik değeri, $h_{0 j}^{*}=h_{0 j}{ }^{\prime}$ nin pozitif ideal çözüm değeri, $M_{j}=j$-inci KVB için yapılan çözümdeki en büyük sapma, $M_{j}^{*}=M_{j}^{\prime}$ nin pozitif ideal çözüm değeri, $\sum_{j=1}^{n} d_{j}=j$-inci KVB için yapılan çözümdeki toplam sapma, $d_{j}^{*}=$ $\sum_{j=1}^{n} d_{j}$ 'nin pozitif ideal çözüm değerini ifade etmektedir. Sadeleştirmeden sonra hibrit model aşağıda verilmiştir. 
$\operatorname{Min}\left[\left(\frac{M_{j}}{M_{j}^{*}}+\frac{\sum_{j=1}^{n} d_{j}}{d_{j}^{*}}-\frac{h_{0 j}}{h_{0 j}^{*}}\right)-1\right]^{p}$

Kisitlar

$\sum_{i=1}^{m} v_{i} x_{i j 0}=1$

$\sum_{r=1}^{s} u_{r} y_{r j}-\sum_{i=1}^{m} v_{i} x_{i j}+d_{j}=0$

$M-d_{j} \geq 0 \quad j=1, \ldots \ldots, n$

$u_{r}, v_{i}, d_{j} \geq 0$

Önerilen hibrit modelin kısıtları (5)'in kısıtlarıyla aynıdır. (6)'un amaç fonksiyonu değerinin minimum seviyede gerçekleşmesi için $\left(\frac{M_{j}}{M_{j}^{*}}+\frac{\sum_{j=1}^{n} d_{j}}{d_{j}^{*}}-\frac{h_{0 j}}{h_{0 j}^{*}}\right)$ minimum olmalıdır. Bu sebeple (8) aşağıda yeniden düzenlenmiştir.

$\operatorname{Min}\left[\left(\frac{M_{j}}{M_{j}^{*}}+\frac{\sum_{j=1}^{n} d_{j}}{d_{j}^{*}}-\frac{h_{0 j}}{h_{0 j}^{*}}\right)\right]^{p}$

Kisitlar

$\sum_{i=1}^{m} v_{i} x_{i j 0}=1$

$\sum_{r=1}^{s} u_{r} y_{r j}-\sum_{i=1}^{m} v_{i} x_{i j}+d_{j}=0$

$M-d_{j} \geq 0 \quad j=1, \ldots ., n$

$u_{r}, v_{i}, d_{j} \geq 0$

Önerilen G-ÇKVZA yöntemin modelini oluşturmak ve çözüm prosedürünü gerçekleştirmek için izlenmesi gereken adımlar aşağıda verilmiştir;

Adım 1: ÇKVZA modeli için girdi-çıktı değişkenlerinin belirlenmesi ve modelin oluşturulması,

Adım 2: (5) kullanılarak her bir amacın pozitif ideal çözüm ve etkinlik değerlerinin belirlenmesi,

Adım 3: 2. Adımda belirlenen pozitif ideal çözümler kullanılarak (6)'ya göre problemin düzenlenmesi ve çözümün yapılması $(1 \leq p<\infty)$, İdeal çözümden uzaklı̆̆ın normalleştirilmiş derecelerinin hesaplanması

Adım 4: G- ÇKVZA modeli sonucu bulunan etkinlik değeri ile ÇKVZA modeli sonucu bulunan etkinlik değerlerinin karşılaştırılması.

Çözüm prosedürünün üçüncü adımından, yapılan uygulamanın özgün sonuçlar ortaya çıkarmasını sağlayan “ideal çözümden uzaklığın normalleştirilmiş dereceleri” ilk kez hesaplanmıştır. İdeal çözümden uzaklığın normalleştirilmiş dereceleri hesaplanırken GÇKVZA modeli çözümünden elde edilen sapma değişkeni değerleri $\left(M_{j}\right.$ ve $\left.d_{j}\right)$ ve çıktı 
değişkeni değerleri $\left(u_{r}\right)$ kullanılarak üstün olmayan çözümler hesaplanmıştır. Birinci amaç (Maks $h_{0}$ ) için üstün olmayan çözümler hesaplanırken, G-ÇKVZA modeli çözümünden elde edilen çıktı değişkeni değerleri $\left(u_{r}\right)$, ÇKVZA modelindeki Max $h_{0}$ amacında yerine yazılmıştır. Maks $h_{0}$ amacı için ideal çözümden uzaklığın normalleştirilmiş derecesi (1) eşitliği veya (6) eşitliğinin ilk oranı kullanılarak hesaplanmıştır. İkinci amaç (Min M) için üstün olmayan çözümler hesaplanırken, G-ÇKVZA modeli çözümünden elde edilen sapmaların maksimumu $(M)$, ÇKVZA modelindeki Min $M$ amacında yerine yazılmıştır. Son olarak üçüncü amaç (Min $\sum d$ ) için üstün olmayan çözümler hesaplanırken, G-ÇKVZA modeli çözümünden elde edilen sapmaların toplamı $\left(\sum d\right)$, ÇKVZA modelindeki Min $\sum d$ amacında yerine yazılmıştır. Min $M$ ve Min $\sum d$ amaçları için ideal çözümden uzaklı̆̆ın normalleştirilmiş derecesi (2) eşitliği veya (6) eşitliğinin ikinci ve üçüncü oranları kullanılarak hesaplanmıştır.

İdeal çözümden uzaklığın normalleştirilmiş derecesi 0 ile 1 arasında değer almaktadır. Her bir amaç fonksiyonu için uzaklığın normalleştirilmiş derecesi 0’a yaklaştıkça kendi pozitif ideal çözümüne yaklaşmaktadır. Uzaklığın normalleştirilmiş derecesi 1'e yaklaştıkça da kendi pozitif ideal çözümünden uzaklaşmaktadır.

\section{Veri Toplama Araçları}

Araştırma verilerinin analiz aşamasından önce ilk olarak KVB sayıları belirlenmiştir. Daha sonra KVB sayıları dikkate alınarak modelde kullanılan girdi-çıktı değişkeni sayıları belirlenmiştir. Son olarak, araştırmada kullanılan girdi-çıktı değişkenlerini belirlemek için akademisyenlerden (çevre mühendisi akademisyenler ve VZA ile ilgili çalışmaları olan akademisyenler) bilgi almak adına uygulanan uzman görüş formu sonuçları kullanılmıştır.

KVB sayısını belirlemek isabetli etkinlik sonuçlarına ulaşabilmek için büyük bir önem arz etmektedir. Farklı yazarlar bu konuda farklı yöntemler kullanmaktadır. Cooper vd. (2002) girdi ve çıktı sayısı toplamının, KVB sayısından az olması gerektiğini, Vassiloglou ve Giokas (1990) ve Golany ve Roll (1989) KVB sayısının, girdi ve çıktı sayıları toplamının en az iki katı olması gerektiğini savunmuştur. KVB sayısının artması girdiler ve çıktılar arasındaki ilişkinin daha net tanımlanmasını sağlamaktadır. Bununla birlikte karar verici gereksiz yere KVB sayısını artırmamaya dikkat etmelidir. KVB sayısının seçiminde göz önüne alınması gereken en önemli husus, KVB'lerin homojenliği olmalıdır (Ramanathan, 2003, s.173).

VZA metodolojisinin önemli aşamalardan birisi de girdi ve çıktı değişkenlerinin seçilmesidir (Christopoulos vd., 2016, s.424). Fakat gerçek dünya problemlerinde girdi ve çıtı değişkenlerinin nasıl seçilmesi gerektiği konusu alanyazında nispeten daha az ilgi görmüştür (Wagner ve Shimshak, 2007, s.57). Girdi ve çıktı değişkenlerinin seçim kriterleri tamamen özneldir. $\mathrm{Bu}$ değişkenlerin seçim prosedürünü belirlemede belirli bir kural yoktur (Ramanathan, 2003, s.173). Genellikle VZA' daki girdi-çıktı değişkenlerinin seçimi uzman görüşleri, geçmiş deneyimler ve ekonomik teoriler tarafından yönlendirilmektedir (Kontodimopoulos vd., 2006, s.171). Bu çalışmada girdi- çıktı değişkenlerinin seçimi amacıyla alanyazında atık yönetimi konusunda VZA metodolojisini kullanan çalışmaların girdi ve çıktı değişkenleri incelenmiştir. Söz konusu çalışmalar Tablo 1'de verilmiştir. 
Tablo 1. Atık Yö netimi Konusunda Yapılmış VZA Çalışmaları

\begin{tabular}{|c|c|c|}
\hline Araştırmacı & Girdi & Çıktı \\
\hline Bosch vd. (2000) & Kamyon sayısı, işçi sayısı, çalışan sayısı & Toplanan atık miktarı \\
\hline $\begin{array}{l}\text { Worthington ve Dollery } \\
\text { (2001) }\end{array}$ & $\begin{array}{l}\text { Yerel atık yönetim hizmet alanı büyüklüğü, mesken oranı, } \\
\text { nüfus yoğunluğu, nüfus dağılımı, elden çıkarma maliyeti, atık } \\
\text { toplama harcamaları }\end{array}$ & $\begin{array}{l}\text { Toplanan toplam çöp miktarı, Toplanan toplam } \\
\text { geri dönüştürülebilir atık miktarı, geri dönüşüm } \\
\text { oranı }\end{array}$ \\
\hline Lozano vd. (2004) & Konteynır sayıs1, nüfus, bar ve restoran sayıs1 & Geri dönüştürülen cam miktarı \\
\hline Chiou vd. (2005) & İşgücü, makine- teçhizat, bütçe, GDT sayısı, & $\begin{array}{l}\text { Toplam katı atık miktarı, toplanan geri } \\
\text { dönüştürülebilir atık miktarı }\end{array}$ \\
\hline García-Sánchez (2008) & Iş gücü, araç sayı1s1, konteynır sayısı & $\begin{array}{l}\text { Toplanan atık miktarı, toplama noktası sayısı, } \\
\text { toplama noktası yoğunluğu, temizlenen alan }\end{array}$ \\
\hline $\begin{array}{l}\text { Marques ve Simões } \\
(2009)\end{array}$ & $\begin{array}{l}\text { Işletme giderleri, yatırım giderleri, nüfus yoğunluğu, kişi } \\
\text { başına GSYİH, atık toplamak için kat edilen mesafe }\end{array}$ & $\begin{array}{l}\text { Arıtılan katı atık miktarı, geri gönüştürülebilir } \\
\text { atık miktarı }\end{array}$ \\
\hline Chen $(2010)$ & $\begin{array}{l}\text { Uretilen katı atık miktarı, atık toplamak için kullanılan işgücü, } \\
\text { makine- teçhizat ve bütçe }\end{array}$ & $\begin{array}{l}\text { Nüfus, sosyal haklar, hane halkı kullanılabilir } \\
\text { gelir, toplanan geri dönüştürülebilir kaynak, } \\
\text { toplanan yemek atıkları, hizmet alanının } \\
\text { büyüklügüü }\end{array}$ \\
\hline Huang vd. (2011) & $\begin{array}{l}\text { Birim başına katı atık toplama maliyeti, birim toplama zamanı } \\
\text { başına toplanan katı atık miktarı, toplama aracı başına toplanan } \\
\text { katı atık miktarı, toplayıcı başına düşen nüfus, katedilen km } \\
\text { başına toplanan katı atık miktarı }\end{array}$ & Anahtar performans göstergeleri \\
\hline $\begin{array}{l}\text { Khadivi ve Ghomi } \\
\text { (2012) }\end{array}$ & Yapı maliyeti, yönetim maliyeti, taşıma maliyeti, arazi maliyeti & $\begin{array}{l}\text { İstihdam olanağ } \text {, geri dönüşüm yeniden } \\
\text { kullanım gelirleri, tesis kapasitesi }\end{array}$ \\
\hline $\begin{array}{l}\text { Rogge ve De Jaeger } \\
(2012)\end{array}$ & Atık maliyetleri & Atık türlerine göre miktarları \\
\hline Ichinose vd. (2013) & Kamyon sayısı, çalışan sayısı & Evsel atık miktarı, endüstriyel atık miktarı \\
\hline Chang vd. (2013) & Oğrenme etkisi, işgücü, makine- teçhizat, Bütçe & $\begin{array}{l}\text { Temizlenen çöp miktarı, geri dönüştürülen atık } \\
\text { miktarı }\end{array}$ \\
\hline
\end{tabular}

Literatürden belirlenen değişkenler ile tesis ziyaretlerinde belirlenen ve çalışmada kullanılabilecek değişkenler göz önünde bulundurularak çalışmanın veri seti oluşturulmuştur. 33 değişkenden oluşan veri setinden hangi değişkenlerin girdi, hangi değişkenlerin çıktı olabileceğini belirlemek için VZA ile ilgilenen akademisyenler ile çevre mühendisi akademisyenlere bir uzman görüş formu vasıtasıyla görüşleri sorulmuştur. 57 akademisyenden alınan görüşler doğrultusunda frekans analizi kullanılarak 26 değişken girdi, 7 değişken ise çıktı olarak belirlenmiştir.

Daha sonra girdi ve çıtı sayılarının KVB'lerin ürettikleri çıktıları doğru özetlediğine emin olarak azaltmak için literatürde sıklıkla kullanılan pearson korelasyon katsayıları incelenmiştir. Çünkü girdi ve çıktıların sayısı ne kadar büyük olursa, yöntemin ayrım gücü o kadar zayıflamaktadır (Thanassoulis, 2001, s.92). Bu yüzden Friedman ve Sinuany-Stern (1998), girdiler veya çıktılar kendileri arasında çok kuvvetli bir korelasyona sahipse bu değişkenlerden birinin analizden çıkarılması gerektiğini savunmuştur. Ayrıca Lewin vd. (1982) girdiler ve çıktılar birbirleri ile negatif korelasyonda olursa girdilerdeki artış çıktıyı negatif yönde etkileyeceğinden bu değişkenlerden birinin model dışı bırakılabileceğini savunmuştur.

Alanyazındaki çalışmalar incelendiğinde girdi-çıktı sayısını azaltmada kullanılan korelasyon katsayıları için genel kabul görmüş eşik değerlere rastlanmamıştır. Bu çalışmada girdi ve çıtılar arasındaki ilişki incelenirken 0.8 'in üzerinde korelasyona sahip değişkenler yüksek ilişkili (Lewin vd., 1982; Nataraja ve Johnson, 2011; Jenkins ve Anderson, 2003; Adler ve Yazhemsky, 2010), 0.2'den düşük korelasyona sahip değişkenler de düşük ilişkili değişkenler (Nataraja ve Johnson, 2011) olarak değerlendirilmiştir. Korelasyon katsayıları sonucu analiz dişında bırakılan girdi ve çıktı değişkenleri dikkate alınarak, kullanılan 19 girdi ve 6 çıktı değişkeni ile bunların hangi birim cinsinden ifade edildiği Tablo 2'de gösterilmiştir. 


\section{Tablo 2. Modelde Kullanılan Girdi ve Çıktıların Birimleri}

\begin{tabular}{|c|c|c|}
\hline Değişken & Birim & Değ. \\
\hline Tesis Kapasitesi & Ton/y1l(*1000) & $\mathrm{V}_{1}$ \\
\hline Ambalaj Atığı Alınan Kurum Sayısı & Adet & $\mathrm{V}_{3}$ \\
\hline Ambalaj Atığı Alınan AVM Sayısı & Adet & $\mathrm{v}_{5}$ \\
\hline Ambalaj Atığı Alınan Market Sayıs1 & Adet & $\mathrm{V}_{6}$ \\
\hline Tesisin Toplu Yaşam Alanlarına Dağıttığı Konteyner/Kumbara/Kafes Sayısı & Adet & $\mathrm{V}_{7}$ \\
\hline Tesisin Arazi Maliyeti & TL/y1l $(* 1000)$ & $\mathrm{V}_{10}$ \\
\hline Tesisin Yönetim ve Malzeme Maliyeti & $\mathrm{TL} / \mathrm{y} 1 \mathrm{l}(* 1000)$ & $\mathrm{V}_{11}$ \\
\hline Tesisin Makine ve Teçhizat Maliyeti & TL/y1l $(* 1000)$ & $\mathrm{V}_{12}$ \\
\hline Tesisin Ambalaj Atığı Toplama Maliyeti & TL/y1l $(* 1000)$ & $\mathrm{V}_{13}$ \\
\hline Tesisin Ambalaj Atığı 1 Ayırma Maliyeti & $\mathrm{TL} / \mathrm{y} 1 \mathrm{l}(* 1000)$ & $\mathrm{V}_{14}$ \\
\hline Tesis Başına Düşen Nüfus & Kişi $(* 1000)$ & $\mathrm{V}_{15}$ \\
\hline Toplanan ve Tesiste Ayrıştırılan Kağıt Miktarı & Ton/y1l $(* 100)$ & $\mathrm{u}_{1}$ \\
\hline Toplanan ve Tesiste Ayrıştırılan Plastik Miktarı & Ton/y1l $(* 100)$ & $\mathrm{u}_{2}$ \\
\hline Toplanan ve Tesiste Ayrıştırılan Cam Miktarı & Ton/y1l $(* 100)$ & $\mathrm{u}_{3}$ \\
\hline Toplanan ve Tesiste Ayrıştırılan Metal Miktarı & Ton/y1l $(* 100)$ & $\mathrm{u}_{4}$ \\
\hline Tesiste Ayrıştırılan ve GDT'lere Satılan Ambalaj Atığından Sağlanan Gelir & TL/y1l $(* 1000)$ & $\mathrm{u}_{5}$ \\
\hline Ayrıştırılan materyalin satıldığı GDT Sayısı & Adet & $\mathrm{u}_{6}$ \\
\hline
\end{tabular}

Tablo 2'de yer alan 19 girdi ve 6 çıtı ile İç Anadolu bölgesinde faaliyetlerine devam eden 87 tesisten 67'si ile etkinlik incelemesi yapılmıştır. Araştırma verileri 2016 yılında toplanmıştır. Verilerin bir tam takvim yılındaki verileri temsil etmesi için tesislerin 2015 yılı bilgileri kullanılmıştır. Tesis sayıları da 2015 yılındaki tesis sayılarıdır. "Tesisin Bulunduğu İlin Yaşam Kalitesi İndeksi” ve "Tesisin Bulunduğu İldeki Önlisans, Lisans ve Lisans Üstü Mezunu Nüfusun 25+ Yaş Nüfusa Oranı” verileri TUİK'den elde edilmiştir. Diğer veriler tesislerden elde edilmiştir. Maliyet ve gelir bilgisi içeren veriler ise yazarlar tarafından hesaplanmıştır.

\section{Bulgular ve Tartışma}

\section{ÇKVZA Modelinin Oluşturulması}

Önerilen G-ÇKVZA modeli çözümünü gerçekleştirmek için öncelikle ÇKVZA modeli çözülmüştür. (5)'de verilen ÇKVZA modelinin üç amaç fonksiyonu bulunmaktadır. Girdiler $v_{j}(j=1,2, \ldots, n)$, çıktılar ise $u_{i}(i=1,2, \ldots, m)$ olarak tanımlanmıştır. Tesislere ait girdi ve çıktıların tanımlayıcı istatistiki bilgileri Tablo 3'te gösterilmiştir; 
Tablo 3. Modelde kullanılan Girdi Değişkenlerinin Tanımlayıcı İstatistiki Bilgileri

\begin{tabular}{|c|c|c|c|c|}
\hline Girdi /Çıktı & Min & Maks & Ort. & SS \\
\hline $\mathrm{v}_{1}$ & 0.67 & 225 & 22.6666 & 31.44334 \\
\hline $\mathrm{v}_{2}$ & 0.40 & 18 & 3.9516 & 3.71967 \\
\hline $\mathbf{v}_{3}$ & 0 & 721 & 79.8955 & 149.62378 \\
\hline $\mathrm{V}_{4}$ & 0 & 24863 & 510.3433 & 3058.96485 \\
\hline$v_{5}$ & 0 & 12 & 1.3030 & 2.49288 \\
\hline $\mathrm{v}_{6}$ & 0 & 350 & 25.8030 & 65.63517 \\
\hline$v_{7}$ & 0 & 600 & 66.1045 & 117.88453 \\
\hline $\mathrm{V}_{8}$ & 0 & 120 & 9.8788 & 23.58220 \\
\hline$V_{9}$ & 8.50 & 28.94 & 15.5425 & 4.24008 \\
\hline $\mathbf{v}_{10}$ & 0.14 & 137.60 & 18.4218 & 26.38189 \\
\hline $\mathrm{v}_{11}$ & 48.50 & 1539.26 & 249.2357 & 277.62113 \\
\hline $\mathrm{v}_{12}$ & 17.82 & 32.67 & 28.9021 & 6.51068 \\
\hline$v_{13}$ & 97.62 & 2760.23 & 497.5585 & 474.67298 \\
\hline $\mathbf{v}_{14}$ & 17.45 & 1221.41 & 157.2991 & 188.23464 \\
\hline $\mathrm{V}_{15}$ & 7.30 & 1380.07 & 174.9160 & 187.74094 \\
\hline$v_{16}$ & 0.51 & 0.63 & 0.5925 & 0.03882 \\
\hline$v_{17}$ & 13.25 & 42.85 & 30.4076 & 11.73560 \\
\hline $\mathrm{V}_{18}$ & 0.86 & 1.40 & 1.0290 & 0.12217 \\
\hline$v_{19}$ & 2.93 & 360 & 77.2200 & 73.19615 \\
\hline $\mathbf{u}_{1}$ & 0 & 160 & 39.6278 & 43.99350 \\
\hline $\mathbf{u}_{2}$ & 0 & 120 & 21.2213 & 26.63946 \\
\hline $\mathbf{u}_{3}$ & 0 & 153.90 & 7.6097 & 22.47717 \\
\hline $\mathbf{u}_{4}$ & 0 & 96.64 & 5.6533 & 13.10848 \\
\hline $\mathbf{u}_{5}$ & 157.05 & 15782.40 & 3277.5179 & 3243.44369 \\
\hline$u_{6}$ & 1 & 46 & 7.1642 & 8.00681 \\
\hline
\end{tabular}

Tablo 3'deki girdi ve çıtılar ile (5)'e göre $\mathrm{KVB}_{1}$ için oluşturulan ÇKVZA modelinin bir kesiti Ek-1'de verilmiştir. Model LINDO w32 yazılımı ile çözülmüştür. $F$, karar uzayındaki uygun çözüm alanı olarak belirlendiğinden, Ek-1'deki modelin kısıtları $x \in F$ olarak tanımlanmıştır.

\section{ÇKVZA Modeli Pozitif İdeal Çözüm ve Etkinliklerin Belirlenmesi}

Maks $h_{0}$ amaç fonksiyonunun çözümüne göre $K V B_{12}, K V B_{13}, K V B_{17}, K V B_{18}, K V B_{25}$, $K V B_{29}, K V B_{31}, K V B_{39}$ ve $K V B_{54}$ haricindeki diğer 58 tesis, Min $M$ amaç fonksiyonunun çözümüne göre sadece $K V B_{8}$ ve $K V B_{19}$, Min $\sum d_{j}$ amaç fonksiyonunun çözümüne göre $K V B_{8}, K V B_{11}, K V B_{15}, K V B_{19}, K V B_{32}, K V B_{33}, K V B_{37}, K V B_{41}$ ve $K V B_{62}$ etkin olarak bulunmuştur. Her üç amaç fonksiyonunun belirlediği etkin KVB'lere göre ortak olan $K V B_{8}$ ve $K V B_{19}$ etkin tesisler olarak ön plana çıkmıştır. Örnek olması açısından ilk 10 KVB için etkinlik ve pozitif ideal çözümler Tablo 4 'te verilmiştir.

Tablo 4. ÇKVZA modeli Pozitif İdeal Çözüm ve Etkinlik Değerleri

\begin{tabular}{lcrrrrr}
\hline \multirow{2}{*}{ KVB } & \multicolumn{2}{c}{$\boldsymbol{h}_{\mathbf{0}}$} & \multicolumn{2}{c}{$\boldsymbol{c} \sum$} \\
\cline { 2 - 7 } & $\begin{array}{c}\text { Pozitif Ideal } \\
\text { Çözüm }\end{array}$ & Etkinlik & $\begin{array}{c}\text { Pozitif Ideal } \\
\text { Çözüm }\end{array}$ & Etkinlik & $\begin{array}{c}\text { Pozitif Ideal } \\
\text { Çözüm }\end{array}$ & Etkinlik \\
\hline KVB1 & 1 & 1 & 0.517241 & 0.61092618 & 11.531490 & 0.533471 \\
\hline KVB2 & 1 & 1 & 0.867099 & 0.13254 & 22.364350 & 0.019998 \\
\hline KVB3 & 1 & 1 & 0.501947 & 0.49961952 & 7.749636 & 0.130249 \\
\hline KVB4 & 1 & 1 & 1.016935 & 0.1590741 & 39.779990 & 0.168823 \\
\hline KVB5 & 1 & 1 & 0.720544 & 0.30510024 & 27.360710 & 0.948803 \\
\hline KVB6 & 1 & 1 & 0.656718 & 0.3429495 & 7.977501 & 0.018654 \\
\hline KVB7 & 1 & 1 & 0.3825 & 0.6153876 & 7.846670 & 0.970643 \\
\hline KVB8 & 1 & 1 & 0.418213 & 1 & 7.740029 & 1 \\
\hline KVB9 & 1 & 1 & 0.390247 & 0.621119 & 4.717732 & 0.586017 \\
\hline KVB10 & 1 & 1 & 0.364366 & 0.636476 & 4.597029 & 0.329942 \\
\hline
\end{tabular}

Tüm KVB'lerin ÇKVZA modelinin etkinlik sonuçları G-ÇKVZA modeli etkinlik sonuçları ile birlikte Ek-2'deki tabloda verilmiştir. 


\section{G- ÇKVZA Modelinin Kurulması ve Çözümü}

G- ÇKVZA amaç fonksiyonu oluşturulurken ÇKVZA modeli amaçlarının, pozitif ideal çözüm değerleri kullanılmaktadır. Öncelikle (6) denklemi kullanılarak amaç fonksiyonları bir araya getirilir. $K V B_{1}$ için oluşturulan G- ÇKVZA amaç fonksiyonu aşağıda verilmiştir. ;

$\operatorname{Min} \frac{1-h_{1}}{1}+\frac{M-0.517241}{0.517241}+\frac{\sum d_{j}-11.53149}{11.53149}$

Daha sonra (7) notasyonu kullanılarak sadeleştirilen model, kısıtlar da eklendikten sonra önerilen (8)'e göre G-ÇKVZA modeli haline getirilmiştir. KVB ${ }_{1}$ için oluşturulan G-ÇKVZA modeli aşağıda verilmiştir.

$$
\begin{aligned}
& \text { Min }\left(1.933334751 M+0.086719 d_{1}+0.086719 d_{2}+0.086719 d_{3}+0.086719 d_{4}+\right. \\
& 0.086719 d_{5}+0.086719 d_{6}+0.086719 d_{7}+0.086719 d_{8}+0.086719 d_{9}+0.086719 d_{10}+ \\
& 0.086719 d_{11}+0.086719 d_{12}+0.086719 d_{13}+0.086719 d_{14}+0.086719 d_{15}+0.086719 d_{16}+ \\
& 0.086719 d_{17}+0.086719 d_{18}+0.086719 d_{19}+0.086719 d_{20}+0.086719 d_{21}+0.086719 d_{22}+ \\
& 0.086719 d_{23}+0.086719 d_{24}+0.086719 d_{25}+0.086719 d_{26}+0.086719 d_{27}+0.086719 d_{28}+ \\
& 0.086719 d_{29}+0.086719 d_{30}+0.086719 d_{31}+0.086719 d_{32}+0.086719 d_{33}+0.086719 d_{34}+ \\
& 0.086719 d_{35}+0.086719 d_{36}+0.086719 d_{37}+0.086719 d_{38}+0.086719 d_{39}+0.086719 d_{40}+ \\
& 0.086719 d_{41}+0.086719 d_{42}+0.086719 d_{43}+0.086719 d_{44}+0.086719 d_{45}+0.086719 d_{46}+ \\
& 0.086719 d_{47}+0.086719 d_{48}+0.086719 d_{49}+0.086719 d_{50}+0.086719 d_{51}+0.086719 d_{52}+ \\
& 0.086719 d_{53}+0.086719 d_{54}+0.086719 d_{55}+0.086719 d_{56}+0.086719 d_{57}+0.086719 d_{58}+ \\
& 0.086719 d_{59}+0.086719 d_{60}+0.086719 d_{61}+0.086719 d_{62}+0.086719 d_{63}+0.086719 d_{64}+ \\
& 0.086719 d_{65}+0.086719 d_{66}+0.086719 d_{67}-19.2 u_{1}-5.72 u_{2}-65.28 u_{3}-5.76 u_{4}- \\
& \left.1863.94 u_{5}-4 u_{6}\right)-1
\end{aligned}
$$

Kisitlar

$x \in F$

(11) birinci KVB için oluşturulmuştur. Benzer düşünceden hareketle diğer 66 KVB için de modeller kurulmuş ve çözülmüştür. G- ÇKVZA model için kullanılan kısıtlar ise $x \in F$ olarak tanımlanan ÇKVZA modelinin kısıtları ile aynı kısıtlardır. Bütün KVB’ler için G-ÇKVZA modeli çözülmüş ve sonuçlar Tablo 5’te gösterilmiştir. 
Tablo 5. G-ÇKVZA Modeli Çözüm ve Etkinlik Değerleri

\begin{tabular}{|c|c|c|c|c|c|c|c|c|}
\hline$\overline{\mathrm{KVB}}$ & Çözüm & Etkinlik & $\overline{K V B}$ & Çözüm & Etkinlik & $\overline{\mathbf{K V B}}$ & Çözüm & Etkinlik \\
\hline$\overline{\text { KVB1 }}$ & 2.451288 & 0.695841 & KVB24 & 2.507501 & 0.651812 & KVB47 & 2.041400 & 0.077533 \\
\hline KVB2 & 2.418567 & 0.157464 & KVB25 & 2.253584 & 0.670060 & KVB48 & 1.899006 & 0.152976 \\
\hline KVB3 & 2.669643 & 0.587825 & KVB26 & 1.952304 & 0.091146 & KVB49 & 1.943946 & 0.069257 \\
\hline$\overline{\text { KVB4 }}$ & 2.016910 & 0.132316 & KVB27 & 1.967214 & 0.090828 & KVB50 & 2.233139 & 0.174237 \\
\hline KVB5 & 1.846294 & 0.307260 & KVB28 & 1.649585 & 0.398858 & KVB51 & 1.564570 & 0.494094 \\
\hline KVB6 & 2.416503 & 0.102112 & KVB29 & 1.802342 & 0.219421 & KVB52 & 1.806894 & 0.330737 \\
\hline KVB7 & 2.431392 & 0.634597 & KVB30 & 1.871271 & 0.390908 & KVB53 & 1.888819 & 0.169710 \\
\hline KVB8 & 1.932142 & 1 & KVB31 & 1.731825 & 0.663643 & KVB54 & 1.954006 & 0.102821 \\
\hline KVB9 & 2.232112 & 0.530352 & KVB32 & 2.192201 & 0.655221 & KVB55 & 2.123342 & 0.190633 \\
\hline KVB10 & 2.046087 & 0.460526 & KVB33 & 2.394770 & 1 & KVB56 & 1.833111 & 0.324458 \\
\hline KVB11 & 2.243089 & 0.835760 & KVB34 & 2.511979 & 0.618173 & KVB57 & 1.755958 & 0.320154 \\
\hline KVB12 & 3.148512 & 0.007837 & KVB35 & 1.886299 & 0.179476 & KVB58 & 2.300532 & 0.101701 \\
\hline$\overline{\text { KVB13 }}$ & 2.353075 & 0.802062 & KVB36 & 1.951526 & 0.117270 & KVB59 & 1.859507 & 0.299506 \\
\hline$\overline{\text { KVB14 }}$ & 2.167920 & 1 & KVB37 & 2.122465 & 1 & KVB60 & 2.376049 & 0.223997 \\
\hline KVB15 & 2.242327 & 0.718229 & KVB38 & 2.441512 & 0.620771 & KVB61 & 1.962872 & 0.090691 \\
\hline KVB16 & 1.664849 & 0.398608 & KVB39 & 2.628973 & 0.746424 & KVB62 & 2.328174 & 0.849060 \\
\hline KVB17 & 1.786520 & 0.380715 & KVB40 & 2.407560 & 0.522654 & KVB63 & 2.480949 & 0.405534 \\
\hline KVB18 & 1.856424 & 0.676608 & KVB41 & 2.088464 & 1 & KVB64 & 1.910371 & 0.246583 \\
\hline KVB19 & 2.063642 & 1 & KVB42 & 2.071028 & 0.136738 & KVB65 & 2.781488 & 0.409469 \\
\hline$\overline{\mathrm{KVB20}}$ & 1.939134 & 0.233785 & $\overline{\text { KVB43 }}$ & 2.799129 & 0.522700 & KVB66 & 2.799400 & 0.259339 \\
\hline KVB21 & 2.181816 & 0.558034 & KVB44 & 1.771516 & 0.305280 & KVB67 & 3.546372 & 0.112153 \\
\hline KVB22 & 1.731125 & 0.463861 & KVB45 & 2.523610 & 0.327982 & & & \\
\hline$\overline{\text { KVB23 }}$ & 2.438972 & 0.103394 & KVB46 & 2.164245 & 0.019454 & & & \\
\hline
\end{tabular}

G- ÇKVZA modeli çözümünden elde edilen etkinlik değerleri hesaplandıktan sonra, bu çalışmada önerilen "ideal çözümden uzaklığın normalleştirilmiş dereceleri” hesaplanmıştır. GÇKVZA modelinden belirlenen çözümlerin sapma değişkeni değerleri her bir KVB'nin ÇKVZA amaçlarında $\left(\operatorname{Max} h_{0}\right.$, Min $M$ ve $\left.\operatorname{Min} \sum d\right)$ yerine yazılarak üstün olmayan çözümler bulunmuştur. Daha sonra, üstün olmayan çözümler ve pozitif ideal çözümler kullanılarak ideal çözümden uzaklığın normalleştirilmiş dereceleri hesaplanmıştır. Bu hesaplamada kullanılan, $K V B_{1}$ 'in G- ÇKVZA modeli çözümünden elde edilen, sapma değişkeni değerleri Tablo 6'da gösterilmiştir.

Tablo 6. KVB $B_{1}$ için Üstün Olmayan Çözümler

\begin{tabular}{cccc}
\hline $\mathrm{M}=0.696634$ & $\mathrm{~d}_{17}=0.384311$ & $\mathrm{~d}_{34}=0.296032$ & $\mathrm{~d}_{51}=0.280653$ \\
\hline $\mathrm{d}_{1}=0.303513$ & $\mathrm{~d}_{18}=0.000000$ & $\mathrm{~d}_{35}=0.407465$ & $\mathrm{~d}_{52}=0.174800$ \\
\hline $\mathrm{d}_{2}=0.222726$ & $\mathrm{~d}_{19}=0.000000$ & $\mathrm{~d}_{36}=0.221725$ & $\mathrm{~d}_{53}=0.203866$ \\
\hline $\mathrm{d}_{3}=0.342102$ & $\mathrm{~d}_{20}=0.452206$ & $\mathrm{~d}_{37}=0.000000$ & $\mathrm{~d}_{54}=0.231765$ \\
\hline $\mathrm{d}_{4}=0.212728$ & $\mathrm{~d}_{38}=0.186249$ & $\mathrm{~d}_{55}=0.696634$ \\
\hline $\mathrm{d}_{5}=0.437433$ & $\mathrm{~d}_{21}=0.427081$ & $\mathrm{~d}_{39}=0.322086$ & $\mathrm{~d}_{56}=0.229031$ \\
\hline $\mathrm{d}_{6}=0.444528$ & $\mathrm{~d}_{22}=0.333366$ & $\mathrm{~d}_{40}=0.489321$ & $\mathrm{~d}_{57}=0.153356$ \\
\hline $\mathrm{d}_{7}=0.450454$ & $\mathrm{~d}_{23}=0.461368$ & $\mathrm{~d}_{41}=0.000000$ & $\mathrm{~d}_{58}=0.489822$ \\
\hline $\mathrm{d}_{8}=0.000000$ & $\mathrm{~d}_{42}=0.449522$ & $\mathrm{~d}_{59}=0.195382$ \\
\hline $\mathrm{d}_{9}=0.449559$ & $\mathrm{~d}_{24}=0.345607$ & $\mathrm{~d}_{43}=0.522577$ & $\mathrm{~d}_{60}=0.696634$ \\
\hline $\mathrm{d}_{10}=0.696634$ & $\mathrm{~d}_{25}=0.432391$ & $\mathrm{~d}_{44}=0.169164$ & $\mathrm{~d}_{61}=0.229308$ \\
\hline $\mathrm{d}_{11}=0.153526$ & $\mathrm{~d}_{26}=0.446899$ & $\mathrm{~d}_{45}=0.560216$ & $\mathrm{~d}_{62}=0.260835$ \\
\hline $\mathrm{d}_{12}=0.354541$ & $\mathrm{~d}_{27}=0.472007$ & $\mathrm{~d}_{46}=0.515496$ & $\mathrm{~d}_{63}=0.480388$ \\
\hline $\mathrm{d}_{13}=0.056919$ & $\mathrm{~d}_{28}=0.355928$ & $\mathrm{~d}_{47}=0.215381$ & $\mathrm{~d}_{64}=0.232916$ \\
\hline $\mathrm{d}_{14}=0.000000$ & $\mathrm{~d}_{29}=0.463395$ & $\mathrm{~d}_{48}=0.212932$ & $\mathrm{~d}_{65}=0.421906$ \\
\hline $\mathrm{d}_{15}=0.099819$ & $\mathrm{~d}_{30}=0.452374$ & $\mathrm{~d}_{49}=0.215024$ & $\mathrm{~d}_{66}=0.136801$ \\
\hline $\mathrm{d}_{16}=0.339052$ & $\mathrm{~d}_{31}=0.154230$ & $\mathrm{~d}_{50}=0.208598$ & $\mathrm{~d}_{67}=0.453399$ \\
\hline & $\mathrm{d}_{32}=0.418559$ & $M i n \sum \mathrm{d}=20.72254$ & \\
\hline & $\mathrm{d}_{33}=0.000000$ & &
\end{tabular}

İdeal çözümden uzaklığın normalleştirilmiş dereceleri hesaplanırken maksimizasyon yönlü tek amaç olan $M a x h_{0}$ amacı için (1), minimizasyon yönlü Min $M$ ve Min $\sum d$ amaçları için de (2) formülleri kullanılmıştır. (1) ve (2) denklemlerinin çözümünün nasıl gerçekleştirildiğini göstermek amaciyla $K V B_{1}, K V B_{2}, K V B_{8}$ ve $K V B_{19}$ 'un her bir amaç fonksiyonu için ideal çözüme uzaklığın normalleştirilmiş derecesi hesaplanmış ve Tablo 7'de gösterilmiştir. 
Tablo 7. Örnek KVB'ler için İdeal Çözümden Uzaklığın Normalleştirilmiş Derecesi

\begin{tabular}{|c|c|c|c|c|c|c|}
\hline$\overline{\mathbf{K V B}}$ & $\begin{array}{l}\text { Amaç } \\
\text { Fonksiyonu }\end{array}$ & $\begin{array}{l}\text { ÇKVZA } \\
\text { Pozitif İdeal } \\
\text { Çözüm }\end{array}$ & $\begin{array}{l}\text { ÇKVZA } \\
\text { Etkinlik }\end{array}$ & $\begin{array}{l}\text { G-ÇKVZA } \\
\text { Etkinlik }\end{array}$ & $\begin{array}{l}\text { G-ÇKVZA } \\
\text { Üstün } \\
\text { Olmayan } \\
\text { Çözüm } \\
\end{array}$ & $\begin{array}{l}\text { Ideal Çözümden } \\
\text { Uzaklığın } \\
\text { Normalleştirilmiş } \\
\text { Derecesi }\end{array}$ \\
\hline \multirow[t]{2}{*}{$\mathrm{KVB}_{1}$} & Min M & 0.517241 & 0.610962 & \multirow[t]{2}{*}{0.695841} & 0.696634 & 0.346826 \\
\hline & $\operatorname{Min} \sum \mathrm{d}$ & 11.531490 & 0.533471 & & 20.72254 & 0.797039 \\
\hline $\mathrm{KVB}_{2}$ & Maks h $_{2}$ & 1 & 1 & 0.157464 & 0.157464 & 0.842536 \\
\hline \multirow{3}{*}{$\mathrm{KVB}_{8}$} & Maks h $_{8}$ & 1 & 1 & \multirow{3}{*}{1} & 1 & $\mathbf{0}$ \\
\hline & $\operatorname{Min} \mathrm{M}$ & 0.418213 & 1 & & 0.573908 & 0.372286 \\
\hline & $\operatorname{Min} \sum \mathrm{d}$ & 7.740029 & 1 & & 12.07332 & 0.559855 \\
\hline \multirow[b]{2}{*}{$\mathbf{K V B}_{19}$} & Maks $\mathrm{h}_{19}$ & 1 & 1 & \multirow[b]{2}{*}{1} & 1 & $\mathbf{0}$ \\
\hline & Min M & 0.549436 & 1 & & 0.926983 & 0.687153 \\
\hline
\end{tabular}

$K V B_{1}$ için yapılan hesaplamalarda $M a k s h_{1}$ amacının normalleştirilmiş derecesi 0.304158 bulunmuştur. Yani uzaklığın normalleştirilmiş dereceleri arasında 0'a en yakın değer $M a x h_{1}$ amacı için bulunmuştur. Bunun anlamı G- ÇKVZA modeli etkinlik değerinin, Max $h_{1}$ amacının çözümünden elde edilen etkinliğe en yakın noktada gerçekleştiğidir. $K V B_{2}$ için bulunan normalleştirilmiş dereceler içerisinde de 0 değeri bulunmadığından çözüm 0 'a en yakın olan $\operatorname{Min} M$ amacına en yakın noktada gerçekleşmiştir. $K V B_{8}$ ve $K V B_{19}$ için bulunan normalleştirilmiş dereceler ise 0 olarak bulunmuştur. Yani iki amaç fonksiyonu için de çözüm Maks $h_{8}$ ve $M a k s h_{19}$ amaçlarının üzerinde çıkmıştır. $K V B_{1}, K V B_{2}, K V B_{8}$ ve $K V B_{19}$ için yapılan hesaplamalar tüm KVB'ler için yapılmış ve sonuçlar Ek-2'deki tabloda verilmiştir.

Ek-2'deki tabloda her bir KVB için hesaplanan ideal çözümden uzaklığın normalleştirilmiş dereceleri incelendiğinde, $K V B_{8}, K V B_{14}, K V B_{19}, K V B_{33}, K V B_{37}$ ve $K V B_{41}$ için $M a x h_{0}=0$ olduğu belirlenmiştir. $\mathrm{Bu}$ sonuç ise G-ÇKVZA etkinlik değerlerinin $M a x h_{0}$ amacında gerçekleştiğini göstermektedir. Yani bu 6 KVB’nin G-ÇKVZA modelde etkin olduğu sonucuna ulaşılmıştır. Diğer amaçlar için (Min M ve Min $\sum d$ ) “0” değerine ulaşılamadığından çözümler 0 'a en yakın olan uzaklıklarda gerçekleşmiştir.

\section{G- ÇKVZA Modeli Sonucu Bulunan Etkinlik Değeri ile ÇKVZA Modeli Sonucu Bulunan Etkinlik Değerlerinin Karşılaştırılması}

ÇKVZA'ya göre her bir amaç fonksiyonunun aynı anda etkin olmasına gerek yoktur. Burada karar verici amaçlardan herhangi birine göre KVB’lerin etkinliğine karar verebilmektedir. Eğer ÇKVZA'da her bir amaç etkin ise tüm modelin etkin olduğu kanaatine varılır. Fakat örneğin, $K V B_{1}$ için $M a x h_{1}=1$ (etkin) iken diğer amaçlar etkin sonuç vermemiştir. Bu durum da karar vericiyi tercih yapmaya zorlamaktadır. Önerilen G-ÇKVZA modeline göre ÇKVZA'nın etkinliğinin belirlenmesinde tek bir etkinlik (Global Etkinlik) elde edilmiştir. G-ÇKVZA'ya göre etkin bir ÇKVZA modelinin varlığından bahsedebilmek için tüm amaçların etkin olması gerekir. Sonuçlar Tablo 8'de özetlenmiştir. 
Tablo 8. ÇKVZA ve G-ÇKVZA'ya Göre Etkin KVB’lerin Karşılaştırılması

\begin{tabular}{|c|c|c|c|c|c|c|c|}
\hline KVB & \multicolumn{3}{|c|}{$\begin{array}{l}\text { İdeal Çözümden Uzaklığın Normalleştirilmiş } \\
\text { Dereceleri }\end{array}$} & \multicolumn{3}{|c|}{ ÇKVZA Etkinlikler } & $\begin{array}{l}\text { G- ÇKVZA } \\
\text { Etkinlik }\end{array}$ \\
\hline KVB 8 & 0 & 0.372286 & 0.559855 & 1 & 1 & 1 & 1 \\
\hline KVB 14 & 0 & 0.348047 & 0.819873 & 1 & 0.76228536 & 0.621910 & 1 \\
\hline KVB 15 & 0.281771 & 0.208292 & 0.752626 & 1 & 0.75472337 & 1 & 0.718229 \\
\hline KVB 19 & 0 & 0.687154 & 0.376489 & 1 & 1 & 1 & 1 \\
\hline KVB 32 & 0.344779 & 0.142912 & 0.703306 & 1 & 0.62669 & 1 & 0.655221 \\
\hline KVB 33 & 0 & 0.494273 & 0.900498 & 1 & 0.71322007 & 1 & 1 \\
\hline KVB 37 & 0 & 0.491465 & 0.631000 & 1 & 0.74105964 & 1 & 1 \\
\hline KVB 41 & 0 & 0.348224 & 0.740241 & 1 & 0.553588 & 1 & 1 \\
\hline KVB 62 & 0.150940 & 0.583521 & 0.594478 & 1 & 0.801564 & 1 & 0.849060 \\
\hline
\end{tabular}

Tablo 8 incelendiğinde, ideal çözümden uzaklığın normalleştirilmiş dereceleri 0 olan KVB'lere göre, G- ÇKVZA etkinlik değerleri $K V B_{8}, K V B_{14}, K V B_{19}, K V B_{33}, K V B_{37}$ ve $K V B_{41}$ $\operatorname{Max} h_{0}$ amacı üzerinde gerçekleşmiştir. Bu KVB'lerden $K V B_{8}$ ve $K V B_{19}$ tüm amaçlara göre, $K V B_{33}, K V B_{37}$ ve $K V B_{41}$ 'de $M a x h_{0}$ ve $\operatorname{Min} \sum d$ amacına göre etkin tesisler olmasına rağmen, çözümlerin hepsi $\operatorname{Max} h_{0}$ amaci üzerinde gerçekleşmiştir. Yine Tablo 8'deki sonuçlar incelendiğinde, $K V B_{11}, K V B_{15}, K V B_{32}$ ve $K V B_{62}$ tesisleri $M a x h_{0}$ ve Min $\sum d$ amaçlarına göre etkin tesisler olarak ortaya çıkmışken, G-ÇKVZA modeline göre etkin değildir. Bu sonuca göre, G-ÇKVZA modelinin Klasik VZA $\left(\operatorname{Max} h_{0}\right)$ 'ya göre ayrım gücü daha yüksek sonuçlar verdiği yorumu yapılabileceği gibi, Min $\sum d$ amacına göre etkin olan tesislerin G-ÇKVZA'ya göre etkin olmaması bir dezavantaj olarak yorumlanabilir.

\section{Sonuç ve Öneriler}

Geri dönüşüm sürecinin başarılı olabilmesi kaynağında ayrı toplanan ambalaj atıklarının tekrar işlem görmeden önce toplanıp türlerine göre ayrıştırılması ile mümkündür. Geri dönüşüm sürecinin bu ilk ve en önemli aşamasını Türkiye'de ÇŞB tarafından yetkilendirilen TAT’lar yürütmektedir. TAT’ların etkin bir şekilde faaliyetlerine devam etmesi geri dönüşüm sürecinin başarısını doğrudan etkilemektedir.

G-ÇKVZA modeli ile yapılan etkinlik analizine İç Anadolu Bölgesinde faaliyetlerine devam eden TAT’lar örnek olarak seçilmiştir. Uygulama için verilerin toplandığı 2015 yılında İç Anadolu Bölgesinde 87 TAT faaliyetlerini sürdürmektedir. Gerçekleştirilen tesis ziyaretleri ve yapılan görüşmeler sonucunda 87 TAT’ın 67'si çalışmaya katılmaya gönüllü olmuştur.

İç Anadolu bölgesinde faaliyet gösteren 67 TAT’ın verileri ile G-ÇKVZA modeli kullanılarak gerçekleştirilen etkinlik analizi sonucunda 6 TAT etkin tesis olarak bulunmuştur. Etkin tesislerin 4'ü Ankara'da, 2'si ise Eskişehir'de faaliyetlerini sürdürmektedir. Yani 6 küçük şehirin (nüfusu 750 000'den az olan Aksaray, Karaman, Kırıkkale, Nevşehir, Niğde, Sivas), 4 büyük şehrin (nüfusu 750 000'den fazla olan Ankara, Eskişehir, Konya, Kayseri) tesislerinin yer aldığ örneklemde, tüm etkin tesisler büyükşehirlerden çıkmıştır. Bunun sebebi, büyükşehirlerde faaliyet gösteren tesislerin belediyeler ile anlaşma yapma firsatlarının (birden fazla belediye olduğundan) daha fazla olması, bunun sonucunda da daha büyük miktarlarda ambalaj atığına erişebilmesi olarak değerlendirilmektedir.

Chen (2010), farklı girdiler ve çıtılar kullanarak belediyelerin toplama ve ayırma performanslarını klasik VZA ile incelemiştir. Çalışmasının sonucunda kentsel bölgelerin atık ayırma etkinliğinin, kırsal bölgelerin ayırma etkinliğinden yüksek olduğunu, toplama 
etkinliklerinin ise kırsal bölgelere göre düşük bulunmuştur. Bu çalışmada ise benzer girdi ve çıtılar kullanılarak (bütçe, toplanan atık miktarı vb.) yapılan etkinlik araştırmasında büyükşehirlerin performansının küçük şehirlerin performansından daha iyi olduğu sonucuna varılmıştır. Yani toplama ve ayırma etkinlikleri ayrı ayrı incelenmemiş olsa bile benzer girdi ve çıktılar ile analiz yapıldığından Chen (2010)'in yaptığı analizle ayırma performansı açısında aynı yönde, toplama performansı açısından tersine bulgulara ulaşılmıştır.

ÇKVZA modeli sonucunda ise $\operatorname{Max} h_{0}$ amacı için 58, Min $M$ amacı için 2 ve Min $\sum d$ amacı için 9 TAT etkin tesisler olarak ortaya çıkmışır. Marbini ve Toloo (2017), tarafından yapılan çalışmada ÇKVZA modeli için Min M amacının Min $\sum d$ amacına göre daha kötümser sonuçlar verdiği bulgularına ulaşılmıştır. Bu uygulama sonuçlarına göre de ÇKVZA modelinde Min $M$ amacı Min $\sum d$ amacına göre daha kötümser sonuçlar verdiğinden, ulaşılan bulgular Marbini ve Toloo (2017) tarafından yapılan çalışma ile aynı yöndedir. Önerilen G-ÇKVZA modeli ise $\operatorname{Max} h_{0}$ ve Min $\sum d$ amaçlarına göre daha kötümser, Min $M$ amacına göre ise daha iyimser etkinlik sonuçları vermiştir.

San Cristóbal (2011), yaptı̆̆ çalı̧̧mada ÇKVZA modeli için bir KVB Min M ve Min $\sum d$ amaçlarının herhangi birinde veya her ikisinde etkin sonuçlar verdiyse, $\operatorname{Max} h_{0}$ amacının da kesinlikle etkin sonuçlar vereceğini savunmuştur. Aynı durumun G-ÇKVZA modeli için de geçerli olduğu yapılan uygulamada kanıtlanmıştır. Yani herhangi bir KVB G-ÇKVZA modelinde etkin sonuç verdiyse, $\operatorname{Max} h_{0}$ amacı (klasik VZA) için de kesinlikle etkin sonuç verecektir. Yapılan uygulama sonucunda elde edilen bulgular San Cristóbal (2011)'in bulguları ile benzer sonuçlar vermiştir.

G-ÇKVZA ve ÇKVZA modellerinin çözümü sonucunda 2 tesis tüm modeller için etkin tesisler olarak bulunmuştur. KVB 8 ve KVB 19 olarak adlandırılan tesislerin her ikiside Ankara'da yer almakta ve Çevre Koruma ve Ambalaj Atıkları Değerlendirme Vakfı (ÇEVKO) tarafından orta ölçekli tesis olarak nitelendirilmektedir. Bu iki tesisin ortak özellikleri tesis kapasitesi, dağıtılan konteynır sayısı gibi girdiler ile ayrıştırılan kağıt ve plastik miktarları, elde edilen gelir gibi çıktılarının araştırmaya katılan tesislerin ortalamalarından daha yüksek değere sahip olmasıdır. Etkin olmayan tesislerin etkin tesisler haline gelebilmesi için kontrol edilebilir girdilerini sabit tutup veya azaltarak, kontrol edilebilir çıktılarını arttırması gerekmektedir. Çünkü tesisler bazı girdi ve çıktılarını kendi insiyatifleri ile arttırıp azaltma şansına sahipken bazı girdi ve çıktıları kontrol edebilme kabiliyetine sahip değillerdir. Örneğin tesisler topladığı atık miktarı veya dağıttığı konteynır sayısını arttırma kabiliyetine sahipken, tesisin bulunduğu ildeki ortalama atık miktarı veya tesisin bulunduğu ilin yaşam indeksi değişkenlerini değiştirme kabiliyetine sahip değildir. Bu kısıtlar göz önünde bulundurulup, kontrol edilebilir çıktılar arttırılarak tesislerin etkinliği yükseltilebilir.

Önerilen G-ÇKVZA modeli ile elde edilen sonuçlara göre etkin olmayan tesislerin, çıktılarını arttırarak etkin tesisler haline gelebilmesi için herhangi bir belediye ile ambalaj atığı toplama işi konusunda anlaşması gerekebilir. Bu etkin olmayan tesislerin, etkin tesisler haline gelebilmesi için en büyük sorumluluklar ÇŞB'ye düşmektedir. Nüfusa göre TAT lisansı verilmesi, belediyelerin birden fazla TAT ile çalışması, kağıt toplayıcılarının belediyeler bünyesinde istihdam edilmesi gibi önlemler hem bazı TAT’ların komisyoncu gibi çalışan tesisler olmasının 
önüne geçebilecek, hem de artan kalite ve nicelik ile TAT’lar faaliyetlerini daha etkin bir şekilde sürdürebileceklerdir.

ÇKVZA ve Global Kriter Yöntem ile modellenip G-ÇKVZA olarak isimlendirilen model TAT etkinliklerinin değerlendirilmesi problemini başarılı bir şekilde çözümlemiştir. Önerilen GÇKVZA modelinin kabul edilebilir sonuçlar vermesi girdi ve çıtı seçiminin titizlikle yapılmasıyla mümkündür. Farklı VZA modellerinin kullanılması, ekonomik ve çevresel şartlara göre modele yeni girdi veya çıtıların ilave edilmesi/çıkarılması TAT’ların etkinlik değerlerinin değişmesine yol açacaktır.

\section{Kaynakça}

Adler, N., Yazhemsky, E. (2010). Improving discrimination in data envelopment analysis: PCA-DEA or variable reduction. European Journal of Operational Research, 202(1), 273284. (https://doi.org/10.1016/j.ejor.2009.03.050)

Alizadeh, M. H., Rasouli, S. M., Tavakkoli-Moghaddam, R. (2011). The use of multi-criteria data envelopment analysis (MCDEA) for location-allocation problems in a fuzzy environment. Expert Systems with Applications, 38(5), 5687-5695. (https://doi.org/10.1016/j.eswa.2010.10.065)

Arora, J. S. (2012). Introduction to optimum design. California : Elsevier Academic.

Bal, H., Örkcü, H. H., Çelebioğlu, S. (2010). Improving the discrimination power and weights dispersion in the data envelopment analysis. Computers \& Operations Research, 37(1), 99107. (https://doi.org/10.1016/j.cor.2009.03.028)

Bosch, N., Pedraja, F., Suárez-Pandiello, J. (2000). Measuring the efficiency of Spanish municipal refuse collection services. Local Government Studies, 26(3), 71-90. (https://doi.org/10.1080/03003930008434000)

Chang, D. S., Liu, W., Yeh, L. T. (2013). Incorporating the learning effect into data envelopment analysis to measure MSW recycling performance. European Journal of Operational Research, 229(2), 496-504. (https://doi.org/10.1016/j.ejor.2013.01.026)

Charnes, A., Cooper, W. W. Rhodes, E. (1978). Measuring the efficiency of decision making units. European Journal of Operational Research, 2(1978), 429-444. (https://doi.org/10.1016/0377-2217(78)90138-8)

Chen, C. C. (2010). A performance evaluation of MSW management practice in Taiwan. Resources, Conservation and Recycling, 54(12), 1353-1361. (https://doi.org/10.1016/j.resconrec.2010.05.003)

Chiou, H. K., Chu, Y. F., Tzeng, G. H. (2005). Comparing AHP/GRA with DEA to evaluate the performance of municipal waste recycling in Taiwan. International Symposium on the Analytic Hierarchy Process, Honolulu, Havai, USA, 1-9. (URL: http://isahp.org/2005Proceedings/Papers/ChiouHK_Chu_Tzeng_ComparingAHPGRA_to_DEA_MunicipalWaste.pdf) 
Christopoulos, A. G., Dokas, I. G., Katsimardou, S., Vlachogiannatos, K. (2016). Investigation of the relative efficiency for the Greek listed firms of the construction sector based on two DEA approaches for the period 2006-2012. Operational Research, 16(3), 423-444. (https://doi.org/10.1007/s12351-015-0207-8)

Cooper, W. W., Seiford, L. M. Tone, K. (2002). Data envelopment analysis: A comprehensive text with models, applications, references and DEA-solver software. Dordrecht: Kluwer Academic Publishers.

De Jaeger, S., Rogge, N. (2014). Cost-efficiency in packaging waste management: The case of Belgium. Resources, Conservation and Recycling, 85(2014), 106-115. (https://doi.org/10.1016/j.resconrec.2013.08.006)

Expósito, A., Velasco, F. (2018). Municipal solid-waste recycling market and the European 2020 Horizon Strategy: A regional efficiency analysis in Spain. Journal of Cleaner Production, 172(2018), 938-948. (https://doi.org/10.1016/j.jclepro.2017.10.221)

French, M. (2018). Fundamentals of Optimization: Methods, Minimum Principles, and Applications for Making Things Better. Switzerland: Springer.

Friedman, L., Sinuany-Stern, Z. (1998). Combining ranking scales and selecting variables in the DEA context: The case of industrial branches. Computers \& Operations Research, 25(9), 781-791. (https://doi.org/10.1016/S0305-0548(97)00102-0)

Garcia-Sánchez, I. M. (2008). The performance of Spanish solid waste collection. Waste Management \& Research, 26(4), 327-336. (https://doi.org/10.1177/0734242X07081486)

Ghasemi, M. R., Ignatius, J., Emrouznejad, A. (2014). A bi-objective weighted model for improving the discrimination power in MCDEA. European Journal of Operational Research, 233(3), 640-650. (https://doi.org/10.1016/j.ejor.2013.08.041)

Ginter, P. M., Starling, J. M. (1978). Reverse distribution channels for recycling. California Management Review, 20(3), 72-82. (https://doi.org/10.2307/41165284)

Golany, B., Roll, Y. (1989). An application procedure for DEA. Omega, 17(3), 237-250. (https://doi.org/10.1016/0305-0483(89)90029-7)

Guiltinan, J. P., Nwokoye, N. G. (1975). Developing distribution channels and systems in the emerging recycling industries. International Journal of Physical Distribution, 6(1), 28-38. (https://doi.org/10.1108/eb014359)

Huang, Y. T., Pan, T. C., Kao, J. J. (2011). Performance assessment for municipal solid waste collection in Taiwan. Journal of environmental management, 92(4), 1277-1283. (https://doi.org/10.1016/j.jenvman.2010.12.002)

Hwang, C. L. Masud, A. S. M. (1979). Multiple objective decision making - methods and applications: a state-of-the-art survey. New York: Springer-Verlag.

Ichinose, D., Yamamoto, M., Yoshida, Y. (2013). Productive efficiency of public and private solid waste logistics and its implications for waste management policy. IATSS Research, 36(2), 98-105. (https://doi.org/10.1016/j.iatssr.2013.01.002) 
Jenkins, L., Anderson, M. (2003). A multivariate statistical approach to reducing the number of variables in data envelopment analysis. European Journal of Operational Research, 147(1), 51-61. (https://doi.org/10.1016/S0377-2217(02)00243-6)

Khadivi, M. R., Ghomi, S. F. (2012). Solid waste facilities location using of analytical network process and data envelopment analysis approaches. Waste management, 32(6), 12581265. (https://doi.org/10.1016/j.wasman.2012.02.002)

Kim, K., Song, I., Kim, J., Jeong, B. (2006). Supply planning model for remanufacturing system in reverse logistics environment. Computers \& Industrial Engineering, 51(2), 279-287. (https://doi.org/10.1016/j.cie.2006.02.008)

Kontodimopoulos, N., Bellali, T., Labiris, G., Niakas, D. (2006). Investigating sources of inefficiency in residential mental health facilities. Journal of Medical Systems, 30(3), 169176. (https://doi.org/10.1007/s10916-005-7981-4)

Lewin, A. Y., Morey, R. C., Cook, T. J. (1982). Evaluating the administrative efficiency of courts. Omega, 10(4), 401-411. (https://doi.org/10.1016/0305-0483(82)90019-6)

Li, X. B., Reeves, G. R. (1999). A multiple criteria approach to data envelopment analysis. European Journal of Operational Research,115(3), 507-517. (https://doi.org/10.1016/S0377-2217(98)00130-1)

Lozano, S., Villa, G., Adenso-Diaz, B. (2004). Centralised target setting for regional recycling $\begin{array}{llll}\text { operations using DEA. Omega, 32(2), } & \text { 101-110. }\end{array}$ (https://doi.org/10.1016/j.omega.2003.09.012)

Marbini, A. H., Toloo, M. (2017). An extended multiple criteria data envelopment analysis model. Expert Systems with Applications, 73, 201-219. (https://doi.org/10.1016/j.eswa.2016.12.030)

Marques, R. C., Simões, P. (2009). Incentive regulation and performance measurement of the Portuguese solid waste management services. Waste Management \& Research, 27(2), 188196. (https://doi.org/10.1177/0734242X08095025)

Miettinen, K. (1998). Nonlinear multiobjective optimization. New York: Springer Science+Business.

Nataraja, N. R., Johnson, A. L. (2011). Guidelines for using variable selection techniques in data envelopment analysis. European Journal of Operational Research, 215(3), 662-669. (https://doi.org/10.1016/j.ejor.2011.06.045)

Ramanathan, R. (2003). An Introduction to Data Envelopment Analysis: A Tool for Performance Measurement. California: Sage.

Rogers, D. S., Tibben-Lembke, R. (2001). An examination of reverse logistics practices. Journal of business logistics, 22(2), 129-148. (https://doi.org/10.1002/j.2158-1592.2001.tb00007.x)

Rogge, N., De Jaeger, S. (2012). Evaluating the efficiency of municipalities in collecting and processing municipal solid waste: A shared input DEA-model. Waste management, 32(10), 1968-1978. (https://doi.org/10.1016/j.wasman.2012.05.021)

Rubem, A. P. S., Brandão, L. C. (2015). Multiple criteria data envelopment analysis-an application to UEFA EURO 2012. Procedia Computer Science, 55(2015), 186-195. (https://doi.org/10.1016/j.procs.2015.07.031) 
San Cristóbal, J. R. (2011). A multi criteria data envelopment analysis model to evaluate the efficiency of the Renewable Energy Technologies. Renewable Energy, 36(10), 2742-2746. (https://doi.org/10.1016/j.renene.2011.03.008)

Shih, C. J., Chang, C. J. (1995). Pareto optimization of alternative global criterion method for fuzzy structural design. Computers \& structures, 54(3), 455-460. (https://doi.org/10.1016/0045-7949(94)00341-Y)

Thanassoulis, E. (2001). Introduction to the theory and application of data envelopment analysis: A foundation text with integrated software. New York: Springer Science+Business Media.

Umarusman, N., Türkmen, A. (2013). Building optimum production settings using De Novo programming with global criterion method. International Journal of Computer Applications, $\quad$ 82(18), 12-15. http://citeseerx.ist.psu.edu/viewdoc/download?doi=10.1.1.402.761\&rep=rep1\&type=pdf

Vassiloglou, M., Giokas, D. (1990). A study of the relative efficiency of bank branches: an application of data envelopment analysis. Journal of the Operational Research Society, 41(7), 591-597. (https://doi.org/10.1057/jors.1990.83)

Verma, M. K., Mukherjee, V., Yadav, V. K. (2016). Greenfield distribution network expansion strategy with hierarchical GA and MCDEA under uncertainty. International Journal of Electrical Power \& Energy Systems, 79(2016), 245-252. (https://doi.org/10.1016/j.ijepes.2016.01.004)

Wadhwa, S., Madaan, J., Chan, F. T. S. (2009). Flexible decision modeling of reverse logistics system: A value adding MCDM approach for alternative selection. Robotics and Computer-Integrated Manufacturing, 25(2), (https://doi.org/10.1016/j.rcim.2008.01.006)

Wagner, J. M., Shimshak, D. G. (2007). Stepwise selection of variables in data envelopment analysis: Procedures and managerial perspectives. European journal of operational research, 180(1), 57-67. (https://doi.org/10.1016/j.ejor.2006.02.048)

Wiel, A. V. D., Bossink, B., Masurel, E. (2012). Reverse logistics for waste reduction in cradleto-cradle-oriented firms: waste management strategies in the Dutch metal industry. International Journal of Technology Management, 60(1-2), 96-113. (https://doi.org/10.1504/IJTM.2012.049108)

Worthington, A. C., Dollery, B. E. (2001). Measuring efficiency in local government: an analysis of New South Wales municipalities' domestic waste management function. Policy Studies Journal, 29(2), 232-249. (https://doi.org/10.1111/j.1541-0072.2001.tb02088.x)

Yadav, V. K., Jha, D. K., Chauhan, Y. K. (2012). A Multi Criteria DEA approach to performance evaluation of Indian thermal power plants. Power System Technology (POWERCON), 2012 IEEE International Conference on, Auckland, New Zealand, 1-5. (https://doi.org/10.1109/PowerCon.2012.6401451)

Zhao, M. Y., Cheng, C. T., Chau, K. W., Li, G. (2006). Multiple criteria data envelopment analysis for full ranking units associated to environment impact assessment. International Journal of Environment and Pollution, 28(3-4), 448-464. (https://doi.org/10.1504/IJEP.2006.011222)

Zikmund, W. G., Stanton, W. J. (1971). Recycling solid wastes: a channels-of-distribution problem. The Journal of Marketing, 35(3), 34-39. (https://doi.org/10.1177/002224297103500306) 
Ek-1. ÇKVZA Modelinin Bir Kesiti

Maks $Z_{1}(x): \operatorname{Max} 19.2 u_{1}+5.76 u_{2}+65.28 u_{3}+5.76 u_{4}+1863.936 u_{5}+4 u_{6}$

$\operatorname{Min} W_{1}(x): \operatorname{Min} M$

$\operatorname{Min} W_{2}(x): \operatorname{Min} \sum d_{j}$

Kisıtlar

$55.408 v_{1}+9.985 v_{2}+30 v_{4}+47 v_{7}+22.091675 v_{9}+3.994 v_{10}+141.86772 v_{11}$

$+32.67 v_{12}+394.2075 v_{13}+122.14104 v_{14}+219.8313253 v_{15}+0.5135 v_{16}$

$+13.7232 v_{17}+1.01 v_{18}+96 v_{19}=1$

$19.2 u_{1}+5.76 u_{2}+65.28 u_{3}+5.76 u_{4}+1863.936 u_{5}+4 u_{6}-55.408 v_{1}-9.985 v_{2}$

$-30 v_{4}-47 v_{7}-22.091675 v_{9}-3.994 v_{10}-141.86772 v_{11}-32.67 v_{12}-394.2075 v_{13}$

$-122.14104 v_{14}-219.8313253 v_{15}-0.5135 v_{16}-13.7232 v_{17}-1.01 v_{18}-96 v_{19}$

$+d_{1}=0$

$10 u_{1}+10 u_{2}+1031 u_{5}+3 u_{6}-2.88 v_{1}-10 v_{2}-10 v_{4}-4 v_{7}-16.5455 v_{9}-4 v_{10}$

$-67.93272 v_{11}-17.82 v_{12}-97.6207 v_{13}-17.44872 v_{14}-11.42640443 v_{15}-$

$0.5135 v_{16}-13.7232 v_{17}-1.01 v_{18}-20 v_{19}+d_{2}=0$

$\vdots$

$23.2 u_{1}+17.4 u_{2}+5.8 u_{3}+2.8 u_{4}+2525.32 u_{5}+8 u_{6}-6 v_{1}-3.963 v_{2}-341 v_{3}$

$-20 v_{4}-80 v_{6}-205 v_{7}-6.912 v_{8}-11.383865 v_{9}-3.1704 v_{10}-246.92484 v_{11}$

$-17.82 v_{12}-304.0362 v_{13}-10469232 v_{14}-346.114 v_{15}-0.5298 v_{16}-15.6595 v_{17}$

$-1.12 v_{18}-58 v_{19}+d_{66}=0$

$27.75 u_{1}+0.35 u_{2}+0.08 u_{2}+0.12 u_{2}+876.961 u_{5}+6 u_{6}-10 v_{1}-5 v_{2}-123 v_{3}$

$-50 v_{4}-2 v_{5}-57 v_{6}-40 v_{7}-0.4 v_{8}-17.8295 v_{9}-7.5 v_{10}-108.13272 v_{11}$

$-32.67 v_{12}-506.727 v_{13}-104.69232 v_{14}-618.617 v_{15}-0.5591 v_{16}-14.2755 v_{17}$

$-1.12 v_{18}-29.2 v_{19}+d_{67}=0$

$M-d_{j} \geq 0 \quad j=1, \ldots \ldots, n$

$u_{r}, v_{i}, d_{j} \geq 0$ 
Ek-2. Tüm KVB'lerin İdeal Çözümden Uzaklığın Normalleștirilmiş Dereceleri

\begin{tabular}{|c|c|c|c|c|c|c|c|}
\hline \multirow[t]{2}{*}{ KVB } & \multicolumn{3}{|c|}{$\begin{array}{c}\text { Ideal Çözümden Uzaklığın Normalleştirilmiş } \\
\text { Dereceleri }\end{array}$} & \multicolumn{3}{|c|}{ ÇKVZA Etkinlikler } & \multirow{2}{*}{$\begin{array}{l}\text { G- ÇKVZA } \\
\text { Etkinlik }\end{array}$} \\
\hline & Maks $\mathrm{h}_{0}$ & Min M & Min $\sum \mathbf{d}$ & Maks h & Min M & $\operatorname{Min} \sum \mathbf{d}$ & \\
\hline$\overline{\text { KVB } 1}$ & 0.304159 & 0.346827 & 0.797039 & 1 & 0.61092618 & 0.533471 & 0.695841 \\
\hline KVB 2 & 0.842536 & 0.109012 & 0.467016 & 1 & 0.13254 & 0.019998 & 0.157464 \\
\hline KVB 3 & 0.412175 & 0.994177 & 0.262748 & 1 & 0.49961952 & 0.130249 & 0.587825 \\
\hline KVB 4 & 0.867684 & 0.010926 & 0.138347 & 1 & 0.1590741 & 0.168823 & 0.132316 \\
\hline$\overline{\text { KVB } 5}$ & 0.692740 & 0.039342 & 0.113760 & 1 & 0.30510024 & 0.948803 & 0.307260 \\
\hline KVB 6 & 0.897888 & 0.368086 & 0.149970 & 1 & 0.3429495 & 0.018654 & 0.102112 \\
\hline KVB 7 & 0.365403 & 0.249561 & 0.815517 & 1 & 0.6153876 & 0.970643 & 0.634597 \\
\hline KVB 8 & 0 & 0.372286 & 0.559855 & 1 & 1 & 1 & 1 \\
\hline KVB 9 & 0.469648 & 0.686288 & 0.078051 & 1 & 0.621119 & 0.586017 & 0.530352 \\
\hline KVB 10 & 0.539474 & 0.476164 & 0.032059 & 1 & 0.636476 & 0.329942 & 0.460526 \\
\hline KVB 11 & 0.164240 & 0.196157 & 0.885061 & 1 & 0.6611152 & 1 & 0.835760 \\
\hline KVB 12 & 0.992163 & 1.152058 & 0.000653 & 0.998301 & 0.537853 & 0.003320 & 0.007837 \\
\hline KVB 13 & 0.197938 & 0.397032 & 0.757123 & 0.9983718 & 0.7947624 & 0.905103 & 0.802062 \\
\hline KVB 14 & 0 & 0.348047 & 0.819873 & 1 & 0.76228536 & 0.621910 & 1 \\
\hline KVB 15 & 0.281771 & 0.208292 & 0.752626 & 1 & 0.75472337 & 1 & 0.718229 \\
\hline KVB 16 & 0.601392 & 0.061565 & 0.002619 & 1 & 0.3694667 & 0.445886 & 0.398608 \\
\hline KVB 17 & 0.602178 & 0.063418 & 0.121786 & 0.957 & 0.38923744 & 0.381508 & 0.380715 \\
\hline KVB 18 & 0.323392 & 0.388994 & 0.151444 & 0.9986616 & 0.7942776 & 0.758282 & 0.676608 \\
\hline KVB 19 & 0 & 0.687154 & 0.376489 & 1 & 1 & 1 & 1 \\
\hline KVB 20 & 0.766215 & 0.053804 & 0.119353 & 1 & 0.2440177 & 0.227731 & 0.233785 \\
\hline KVB 21 & 0.441966 & 0.176131 & 0.563547 & 1 & 0.5428876 & 0.971695 & 0.558034 \\
\hline KVB 22 & 0.536139 & 0.081576 & 0.114262 & 1 & 0.3934435 & 0.983864 & 0.463861 \\
\hline KVB 23 & 0.896606 & 0.034906 & 0.507386 & 1 & 0.13358694 & 0.083732 & 0.103394 \\
\hline KVB 24 & 0.348188 & 0.315270 & 0.843998 & 1 & 0.542884 & 0.507108 & 0.651812 \\
\hline KVB 25 & 0.329940 & 0.167429 & 0.756942 & 0.998836 & 0.678423 & 0.988426 & 0.670060 \\
\hline KVB 26 & 0.908854 & 0.027946 & 0.015562 & 1 & 0.08632853 & 0.063841 & 0.091146 \\
\hline KVB 27 & 0.909172 & 0.023810 & 0.034228 & 1 & 0.1121265 & 0.071258 & 0.090828 \\
\hline KVB 28 & 0.601142 & 0.053214 & 0.004931 & 1 & 0.39656916 & 0.454158 & 0.398858 \\
\hline KVB 29 & 0.761258 & 0.052315 & 0.010931 & 0.9190716 & 0.22067563 & 0.179147 & 0.219421 \\
\hline KVB 30 & 0.609092 & 0.045233 & 0.216602 & 1 & 0.4079759 & 0.961986 & 0.390908 \\
\hline KVB 31 & 0.336357 & 0.091016 & 0.303953 & 0.99749178 & 0.4091098 & 0.983020 & 0.663643 \\
\hline KVB 32 & 0.344779 & 0.142912 & 0.703306 & 1 & 0.62669 & 1 & 0.655221 \\
\hline KVB 33 & 0 & 0.494273 & 0.900498 & 1 & 0.71322007 & 1 & 1 \\
\hline KVB 34 & 0.381827 & 0.067309 & 1.198226 & 1 & 0.5936606 & 0.494752 & 0.618173 \\
\hline KVB 35 & 0.820524 & 0.028971 & 0.036808 & 1 & 0.16264112 & 0.181323 & 0.179476 \\
\hline KVB 36 & 0.882730 & 0.049381 & 0.019412 & 1 & 0.11633562 & 0.118045 & 0.117270 \\
\hline KVB 37 & 0 & 0.491465 & 0.631000 & 1 & 0.74105964 & 1 & 1 \\
\hline KVB 38 & 0.379229 & 0.738590 & 0.322575 & 1 & 0.8519435 & 0.638216 & 0.620771 \\
\hline KVB 39 & 0.253576 & 0.725517 & 0.652396 & 0.998545 & 0.52564259 & 0.919166 & 0.746424 \\
\hline KVB 40 & 0.477346 & 0.610872 & 0.319451 & 1 & 0.703754 & 0.152840 & 0.522654 \\
\hline KVB 41 & 0 & 0.348224 & 0.740241 & 1 & 0.553588 & 1 & 1 \\
\hline KVB 42 & 0.863262 & 0.033960 & 0.173799 & 1 & 0.16520758 & 0.153626 & 0.136738 \\
\hline KVB 43 & 0.477300 & 0.769046 & 0.552505 & 1 & 0.52486998 & 0.533551 & 0.522700 \\
\hline KVB 44 & 0.694720 & 0.038692 & 0.038297 & 1 & 0.186748 & 0.305330 & 0.305280 \\
\hline KVB 45 & 0.672018 & 0.596343 & 0.254088 & 1 & 0.3823354 & 0.301737 & 0.327982 \\
\hline KVB 46 & 0.980546 & 0.157486 & 0.026084 & 1 & 0.1529355 & 0.010448 & 0.019454 \\
\hline KVB 47 & 0.922467 & 0.006578 & 0.112357 & 1 & 0.077555 & 0.112167 & 0.077533 \\
\hline KVB 48 & 0.847024 & 0.019073 & 0.032912 & 1 & 0.10754652 & 0.155682 & 0.152976 \\
\hline KVB 49 & 0.930743 & 0.001701 & 0.011502 & 1 & 0.06995832 & 0.063554 & 0.069257 \\
\hline KVB 50 & 0.825763 & 0.017828 & 0.389549 & 1 & 0.172047 & 0.020557 & 0.174237 \\
\hline KVB 51 & 0.505906 & 0.049615 & 0.010126 & 1 & 0.375232 & 0.378818 & 0.494094 \\
\hline KVB 52 & 0.669263 & 0.029759 & 0.107444 & 1 & 0.34931226 & 0.340091 & 0.330737 \\
\hline KVB 53 & 0.830290 & 0.022652 & 0.035873 & 1 & 0.16374744 & 0.176986 & 0.169710 \\
\hline KVB 54 & 0.895597 & 0.013937 & 0.044623 & 0.984847 & 0.1168045 & 0.107015 & 0.102821 \\
\hline KVB 55 & 0.809367 & 0.311289 & 0.003696 & 1 & 0.3834976 & 0.188534 & 0.190633 \\
\hline KVB 56 & 0.675542 & 0.002089 & 0.155985 & 1 & 0.3305194 & 0.371787 & 0.324458 \\
\hline KVB 57 & 0.679846 & 0.033582 & 0.042497 & 1 & 0.28214977 & 0.321329 & 0.320154 \\
\hline KVB 58 & 0.898299 & 0.036951 & 0.365282 & 1 & 0.13376948 & 0.094710 & 0.101701 \\
\hline KVB 59 & 0.700494 & 0.043499 & 0.115251 & 1 & 0.31340276 & 0.923477 & 0.299506 \\
\hline KVB 60 & 0.776003 & 0.400121 & 0.200191 & 1 & 0.4457909 & 0.081404 & 0.223997 \\
\hline KVB 61 & 0.909309 & 0.024166 & 0.029393 & 1 & 0.11205843 & 0.087889 & 0.090691 \\
\hline KVB 62 & 0.150940 & 0.583521 & 0.594478 & 1 & 0.801564 & 1 & 0.849060 \\
\hline KVB 63 & 0.594466 & 0.571758 & 0.312692 & 1 & 0.58663269 & 0.550872 & 0.405534 \\
\hline KVB 64 & 0.753417 & 0.023897 & 0.133064 & 1 & 0.264149 & 0.121602 & 0.246583 \\
\hline
\end{tabular}

